\title{
Mechanistic Evaluation of the Complex Drug-Drug Interactions of Maraviroc: Contribution of Cytochrome P450 3A, P-Glycoprotein and Organic Anion Transporting Polypeptide 1B1 ${ }^{\mathrm{S}}$
}

\author{
(1) Emi Kimoto, Manoli Vourvahis, Renato J. Scialis, ${ }^{1}$ Heather Eng, A. David Rodrigues, \\ and (D) Manthena V. S. Varma \\ Pharmacokinetics, Pharmacodynamics and Metabolism, Medicine Design, Pfizer Inc., Groton, Connecticut (E.K., R.J.S., H.E., \\ A.D.R., M.V.S.V.); and Clinical Pharmacology, Pfizer Inc., New York, New York (M.V.)
}

Received November 1, 2018; accepted March 4, 2019

\section{ABSTRACT}

The aim of the present study was to quantitatively evaluate the drugdrug interactions (DDIs) of maraviroc (MVC) with various perpetrator drugs, including telaprevir (TVR), using an in vitro data-informed physiologically based pharmacokinetic (PBPK) model. MVC showed significant active uptake and biliary excretion in sandwich-cultured human hepatocytes, and biphasic organic anion transporting polypeptide (OATP)1B1-mediated uptake kinetics in transfected cells (high-affinity $K_{\mathrm{m}} \sim 5 \mu \mathrm{M}$ ). No measureable active uptake was noted in OATP1B3- and OATP2B1-transfceted cells. TVR inhibited OATP1B1-mediated MVC transport in vitro, and also exhibited CYP3A time-dependent inhibition in human hepatocytes (inactivation constant, $K_{\mathrm{I}}=2.24 \mu \mathrm{M}$, and maximum inactivation rate constant, $k_{\text {inact }}=0.0112$ minute $\left.{ }^{-1}\right)$. The inactivation efficiency $\left(k_{\text {inact }} / K_{\downarrow}\right)$ was approximately 34-fold lower in human hepatocytes compared with liver microsomes. A PBPK model accounting for interactions involving CYP3A, P-glycoprotein (P-gp), and OATP1B1 was developed based on in vitro mechanistic data. MVC DDls with ketoconazole (inhibition of CYP3A and P-gp), ritonavir (inhibition of CYP3A and P-gp), efavirenz (induction of CYP3A), rifampicin (induction of CYP3A and P-gp; inhibition of OATP1B1), and TVR (inhibition of CYP3A, P-gp, and OATP1B1) were well described by the PBPK model with optimized transporter $K_{\mathrm{i}}$ values implying that OATP1B1-mediated uptake along with CYP3A metabolism determines the hepatic clearance of MVC, and P-gp-mediated efflux limits its intestinal absorption. In summary, MVC disposition involves intestinal P-gp/CYP3A and hepatic OATP1B1/CYP3A interplay, and TVR simultaneously inhibits these multiple mechanisms leading to a strong DDI-about 9.5fold increase in MVC oral exposure.

\section{Introduction}

Drug-drug interactions (DDIs) involving drug-metabolizing enzymes and membrane transporters can lead to changes in victim drug exposure, which can result in adverse effects and impact efficacy. Therefore, it is important to evaluate potential DDIs in drug discovery and during clinical development, as reflected in the guidance documents provided by various health authorities [for example, European Medicines Agency (http://www. ema.europa.eu/docs/en_GB/document_library/Scientific_guideline/ 2012/2007/WC500129606.pdf); Japanese Ministry of Health (https://www. solvobiotech.com/documents/Japanese_DDI_guideline_(draft)_2014Jan.pdf); and Center for Drug Evaluation and Research (http://www.fda.gov/ downloads/Drugs/Guidance-ComplianceRegulatoryInformation/Guidances/ ucm292362.pdf)]. While successful approaches have been developed to predict DDIs involving cytochrome P450 enzyme inhibition or

${ }^{1}$ Current affiliation: Metabolism and Pharmacokinetics, Preclinical Candidate Optimization, Bristol-Myers Squibb, Princeton, New Jersey.

The authors have no conflicts of interest that are directly relevant to this study. https://doi.org/10.1124/dmd.118.085241.

S This article has supplemental material available at dmd.aspetjournals.org. induction in isolation, the optimal strategy to evaluate complex DDIs such as mixed enzyme inhibition and induction, combined competitive and time-dependent inhibition (TDI), or simultaneous transporter-enzyme interactions continue to evolve (Fahmi et al., 2009; Vieira et al., 2014; Varma et al., 2015; Wagner et al., 2015).

Maraviroc (MVC) is a selective $\mathrm{C}-\mathrm{C}$ chemokine receptor type 5 antagonist approved for the treatment of human immunodeficiency virus infection (Abel et al., 2009). MVC is primarily metabolized by CYP3A with renal clearance accounting for about $23 \%$ of total clearance, and it is a substrate of P-glycoprotein (P-gp) and organic anion transporting polypeptide (OATP)1B1 (Walker et al., 2005; Hyland et al., 2008; Siccardi et al., 2010). MVC exposure was shown to increase significantly when coadministered with strong CYP3A/P-gp inhibitors in humans (Hyland et al., 2008). Clinical studies have also indicated that the mean area under the plasma concentration-time curve (AUC) of MVC increased by approximately 9.5 -fold when treated with telaprevir (TVR) (Vourvahis et al., 2014). The magnitude of this interaction is much greater than that observed with other strong CYP3A probe inhibitors (e.g., 2.5-fold with ritonavir and 5-fold with ketoconazole) (Abel et al., 2008b; Vourvahis et al., 2014). Earlier studies have shown an association between MVC plasma trough concentrations and the SLCO1B1 521TC genotype

ABBREVIATIONS: AUC, area under the plasma concentration-time curve; AUCR, area under the plasma concentration-time curve ratio; DDI, drugdrug interaction; HBSS, Hanks' balanced salt solution; HEK, human embryonic kidney; HLM, human liver microsomes; LC-MS/MS, liquid chromatography-tandem mass spectrometry; MO, R-diastereomer (VRT-127394); MVC, maraviroc; OATP, organic anion transporting polypeptide; PBPK, physiologically based pharmacokinetic; P-gp, P-glycoprotein; $R_{\text {pred/obs }}$, ratio of predicted and observed values; $\mathrm{SCHH}$, sandwich-cultured human hepatocytes; TDI, time-dependent inhibition; TVR, telaprevir. 
in patients treated with $60 \mathrm{mg}$ MVC plus etravirine or efavirenz (Siccardi et al., 2010). More recent genotype-pharmacokinetic analyses have shown that homozygous or heterozygous carriers of the SLCO1B1 $521 \mathrm{~T}>\mathrm{C}$ allele are characterized by higher MVC exposure $\left(\mathrm{AUC}_{0-12}\right.$, $C_{\max }$, and $C_{\min }$ ) versus reference TT homozygote subjects (Vourvahis et al., 2011). These clinical findings indicate that OATP1B1 plays a significant role in the hepatic clearance of MVC. Human immunodeficiency virus-infected patients are likely to be at risk for other infectious pathogens, including hepatitis $\mathrm{B}$ or $\mathrm{C}$ virus. For example, the results of a recent meta-analysis study indicated more than 2 million people are coinfected with human immunodeficiency virus and hepatitis $\mathrm{C}$ virus globally (Platt et al., 2016). Although use of TVR, a direct-acting antiviral for the treatment of genotype 1 chronic hepatitis $\mathrm{C}$ virus patients, has been discontinued, a number of DDIs were reported that may involve inhibition of not only CYP3A but also P-gp and OATP1B1.

The aim of this study was to quantitatively evaluate MVC pharmacokinetic interactions based on mechanistic in vitro studies and physiologically based pharmacokinetic (PBPK) modeling and simulations. First, transporter-mediated disposition of MVC was characterized in vitro using transfected cells and primary human hepatocytes. Second, a permeability-limited hepatic disposition model was considered in the PBPK analyses and verified using a range of available clinical DDI data with various perpetrator drugs including ketoconazole, ritonavir, efavirenz, and rifampicin, as well as TVR, which caused up to 9.5-fold increase in MVC plasma exposure. Prior to this, the TVR perpetrator model was verified using DDI data with probe substrate drugs: midazolam (CYP3A), digoxin (P-gp), and atorvastatin (CYP3A/P-gp/OATP1B1).

\section{Materials and Methods}

Materials and Reagents. In VitroGro-HT (thawing), In VitroGro-CP (plating), and In VitroGro-HI (incubation) hepatocyte media were purchased from Celsis In Vitro Technologies Inc. (Baltimore, MD). Hanks' balanced salt solution (HBSS) containing $\mathrm{Ca}^{2+} / \mathrm{Mg}^{2+}$ (standard) was purchased from Lonza (Walkersville, MD), and HBSS $\left(\mathrm{Ca}^{2+} / \mathrm{Mg}^{2+}\right.$-free $)$ and William's medium $\mathrm{E}$ were purchased from Gibco (Grand Island, NY). BioCoat 24-well plates and Matrigel were purchased from Corning (Kennebunk, ME). The BCA Protein Assay Kit was purchased from PierceBiotechnology (Rockford, IL). High-performance liquid chromatography grade methanol, acetonitrile, and water were obtained from Fisher Chemical (Fair Lawn, NJ). TVR was purchased from Toronto Research Chemicals Inc. (Ontario, Canada). Midazolam was purchased from United States Pharmacopeia (Rockville, MD), and 1'-hydroxymidazolam and D4-1'-hydroxymidazolam were synthesized at Pfizer Inc. MVC, formic acid, Dulbecco's PBS, Krebs-Henseleit buffer, monobasic and dibasic potassium phosphate buffer, magnesium chloride, HEPES, reduced NADPH, and all other chemicals were purchased from SigmaAldrich (St. Louis, MO). Cryopreserved human hepatocyte lot HU4241 (male, Caucasian, age 53) was purchased from Invitrogen (Waltham, MA) and HH1025 (female, Caucasian, age 59) was purchased from In Vitro ADMET (Columbia, MD). Pooled male and female human liver microsomes (HLM) $(n=50$ donors) were purchased from Sekisui Xenotech (Kansas City, KS), and pooled male and female hepatocytes ( $n=10$ donors) were purchased from Bioreclamation IVT (Baltimore, MD).

Transport Studies in Sandwich-Cultured Human Hepatocytes. Plateable cryopreserved hepatocytes were thawed and plated as described previously (Kimoto et al., 2015). Briefly, hepatocytes were thawed in a water bath at $37^{\circ} \mathrm{C}$ and placed on ice. The cells were then poured into In VitroGro-HT medium at $37^{\circ} \mathrm{C}$ at a ratio of one vial $/ 50 \mathrm{ml}$ in a conical tube. The cells were centrifuged at $50 \mathrm{~g}$ for 3 minutes and resuspended at $0.75 \times 10^{6}$ cells $/ \mathrm{ml}$ in In VitroGro-CP medium. Cell viability was determined by trypan blue exclusion and exceeded $85 \%$. On day 1 , hepatocyte suspensions were plated in collagen-coated 24-well plates at a density of $0.375 \times 10^{6}$ cells/well in a volume of $0.5 \mathrm{ml} / \mathrm{well}$. After 18-24 hours of incubation at $37^{\circ} \mathrm{C}$, cells were overlaid with ice-cold $0.25 \mathrm{mg} / \mathrm{ml}$ Matrigel in In VitroGro-HI medium at $0.5 \mathrm{ml} / \mathrm{well}$. Cultures were maintained in In VitroGro-HI medium that was refreshed every 24 hours. On day 5, the sandwich-cultured human hepatocytes $(\mathrm{SCHH})$ were first rinsed twice with
HBSS containing $\mathrm{Ca}^{2+} / \mathrm{Mg}^{2+}$ (standard) or $\mathrm{Ca}^{2+} / \mathrm{Mg}^{2+}$-free HBSS, and then preincubated for 10 minutes with standard or $\mathrm{Ca}^{2+} / \mathrm{Mg}^{2+}$-free HBSS in the absence or presence of inhibitors at $37^{\circ} \mathrm{C}$ or $4^{\circ} \mathrm{C}$. After aspirating the preincubation buffer, $0.5 \mathrm{ml}$ of incubation buffer containing substrate was added in the absence or presence of inhibitors at $37^{\circ} \mathrm{C}$ or $4^{\circ} \mathrm{C}$. The uptake was terminated at a designated time $(0.5,1,2,5,10$, and 15 minutes) by adding $0.5 \mathrm{ml}$ of ice-cold standard HBSS after removal of the incubation buffer. Cells were then washed three times with $0.5 \mathrm{ml}$ of ice-cold standard HBSS. The hepatocytes were lysed with methanol containing the internal standard for liquid chromatography-tandem mass spectrometry (LC-MS/MS) quantification (Supplemental Material).

Transport Studies in Suspended Human Hepatocytes. Uptake of MVC was measured using suspended human hepatocytes as described previously (Kimoto et al., 2011; Bi et al., 2013). Briefly, cryopreserved hepatocytes were thawed at $37^{\circ} \mathrm{C}$ and then immediately suspended in In VitroGro-HT medium. The hepatocytes were centrifuged at $50 \mathrm{~g}$ for 3 minutes at room temperature, and the cells were resuspended in Krebs-Henseleit buffer. Cell viability was determined by trypan blue exclusion and exceeded $85 \%$. The hepatocytes were diluted to $2 \times 10^{6}$ cells $/ \mathrm{ml}$. An aliquot of cells $(200 \mu \mathrm{l})$ was placed in test tubes and prewarmed in a slow-motion $37^{\circ} \mathrm{C}$ water bath or ice-cold bath for 3 minutes. Uptake incubations were initiated by the addition of $200 \mu \mathrm{l}$ of MVC $(2 \mu \mathrm{M})$ prewarmed $\left(37^{\circ} \mathrm{C}\right)$ or ice-cold, which resulted in a final substrate concentration of $1 \mu \mathrm{M}$ and a cell density of $1 \times 10^{6}$ cells $/ \mathrm{ml}$ in a $400 \mu \mathrm{l}$ incubation volume. The incubations were terminated at $0.5,1$, and 1.5 minutes by collection of $100 \mu \mathrm{l}$ of incubation mixture into a centrifuge tube that was previously prepared with two layers: a bottom layer of $50 \mu 1$ of $2 \mathrm{~N} \mathrm{NaOH}$ and an upper layer of $100 \mu \mathrm{l}$ oil (density $=1.015$; a mixture of silicone oil and mineral oil). The tube was immediately centrifuged at $16,000 \mathrm{~g}$ for 10 seconds (Microfuge E; Beckman Coulter, Fullerton, CA). The centrifuge tubes were cut at the middle of the oil layer to separate the bottom layer containing cells. Ammonium acetate in the bottom layer was aspirated and the cell pellets were transferred to a 96-well plate after resuspending with $50 \mu \mathrm{l}$ of water. The cells were lysed with $100 \mu \mathrm{l}$ of methanol containing internal standard. The concentrations of analytes were determined by LC-MS/MS in Supplemental Material.

Transport Studies in Transfected Human Embryonic Kidney 293 Cells. OATP1B1, OATP1B3, and OATP2B1 specific transport was assessed in stably transfected human embryonic kidney (HEK) 293 cells. Transporter-transfected and wild-type HEK293 cells were seeded onto 24-, 48-, or 98-well poly-D-lysinecoated plates at a density of $2 \times 10^{5}$ cells ( 24 -well plate) per well in a total volume of $0.5 \mathrm{ml}$ per well, $1.125 \times 10^{5}$ cells (48-well plate) per well in a total volume of $0.25 \mathrm{ml}$ per well, or $2.5-5 \times 10^{4}$ cells per well in a total volume of $0.1 \mathrm{ml}$ per well (96-well plate). OATP-transfected cells were cultured for 48-72 hours in the presence of Dulbecco's modified Eagle's medium, 10\% heat-inactivated FBS, and $5 \mu \mathrm{g} / \mathrm{ml}$ blasticidin. After the cells reached confluency, they were washed two times with uptake buffer [HBSS with $20 \mathrm{mM}$ 4-(2-hydroxyethyl)-1piperazineethanesulfonic acid, $\mathrm{pH}$ 7.4]. The transport study was initiated by incubating the cells with incubation buffer containing each test compound at $37^{\circ} \mathrm{C}$ in triplicate. At the completion of the incubation, cells were quickly washed three times with ice-cold buffer. The cells were then lysed with methanol containing the internal standard for LC-MS/MS quantification (Supplemental Material). The uptake of compounds was normalized by total cell protein using the BCA Protein Assay Kit following the manufacturer's protocol.

Time-Dependent Inhibition Study in Human Liver Microsomes and Human Hepatocytes. The TDI of CYP3A in HLM was measured in pooled $\operatorname{HLM}(0.3 \mathrm{mg} / \mathrm{ml})$ in the presence of $\mathrm{MgCl}_{2}(3.3 \mathrm{mM})$ and NADPH $(1.3 \mathrm{mM})$ in potassium phosphate buffer $(100 \mathrm{mM}, \mathrm{pH}$ 7.4). TVR stock solutions, prepared at 100 times the incubation concentration in $90 \%$ acetonitrile and $10 \%$ water, were added to this incubation mixture to initiate the reaction. The final incubation concentration range was $0.03-30 \mu \mathrm{M}$. At various time points $(1,2,4,9,14,21$, and 30 minutes) an aliquot of this mixture was transferred to an activity incubation mixture consisting of midazolam $(20.9 \mu \mathrm{M}$, which is approximately 10 -fold the $K_{\mathrm{m}}$ value in $\left.\mathrm{HLM}\right), \mathrm{MgCl}_{2}(3.3 \mathrm{mM})$, and NADPH $(1.3 \mathrm{mM})$ in potassium phosphate buffer (100 mM, pH 7.4), resulting in 20-fold dilution. The TDI of CYP3A in human hepatocytes was measured in pooled human hepatocytes $\left(0.45 \times 10^{6}\right.$ cells $\left./ \mathrm{ml}\right)$ suspended in William's medium E supplemented with L-glutamine and HEPES. TVR stock solutions prepared at 10 times the incubation concentration in $90 \%$ media, $9 \%$ acetonitrile, and $1 \%$ water were added to this 
incubation mixture to initiate the reaction. The final incubation concentration range was $0.1-30 \mu \mathrm{M}$ in a volume of $50 \mu \mathrm{l}$. At various time points $(1,8,18,30$, 60, and 90 minutes), a $200 \mu \mathrm{l}$ aliquot of activity incubation mixture consisting of midazolam (final concentration $80 \mu \mathrm{M}$, which is approximately 5-fold the $K_{\mathrm{m}}$ value in human hepatocytes) in media was added to incubation wells, resulting in 5 -fold dilution. All reactions were conducted in duplicate at $37^{\circ} \mathrm{C}$ with a final volume of $200 \mu \mathrm{l}$ (HLM) or $250 \mu \mathrm{l}$ (hepatocytes). After incubation ( 6 minutes for HLM and 20 minutes for human hepatocytes), the activity reaction was terminated by the addition of two volumes of acetonitrile containing internal standard (100 ng/ml of D4-1'-hydroxymidazolam). Samples were vortexed and centrifuged for 5 minutes at approximately $2300 \mathrm{~g}$ at room temperature. Supernatant was mixed with an equal volume of water containing $0.2 \%$ formic acid and analyzed directly by LC-MS/MS (Supplemental Material). For estimation of kinetic constants, data analysis methods were used as previously described (Yates et al., 2012).

PBPK Modeling and Simulations. Whole-body PBPK modeling and simulations were performed using the population-based absorption, distribution, metabolism, and excretion simulator, Simcyp (version 15; Certara, Sheffield, UK). Each simulation was performed for 50 subjects ( 5 trials $\times 10$ subjects) in the software's built-in healthy volunteer virtual population. Dose, dosing interval, and dosing duration of substrate and perpetrator drugs were similar to that used in the reported clinical studies.

MVC PBPK Model Development. The physicochemical and pharmacokinetic parameters of MVC used for the present PBPK model are summarized in Table 1. The advanced dissolution, absorption, and metabolism model and the permeability-limited liver distribution model were used to parameterize drug absorption and liver disposition, respectively. The effective permeability in human was predicted using the apparent permeability in the Caco-2 system (calibrated by propranolol as the permeability marker: $23 \times 10^{-6} \mathrm{~cm} / \mathrm{s}$, in-house data) (Walker et al., 2005). Colonic absorption of MVC was assumed to be negligible (regional permeability of colon in the advanced dissolution, absorption, and metabolism model $=0.01 \times 10^{-4} \mathrm{~cm} / \mathrm{s}$ ). The full PBPK model was adopted to obtain the distribution of MVC into all organs except liver using the method developed by Rodgers et al. (2005) and Rodgers and Rowland (2006) and considering rapid equilibrium between blood and tissues with tissue-to-plasma partitioning coefficients $(K \mathrm{p})$. The observed mean pharmacokinetic data of MVC in healthy subjects receiving 3,10, and $30 \mathrm{mg}$ MVC via intravenous infusion or $150 \mathrm{mg}$ oral dose were used to refine the absorption and distribution parameters (Abel et al., 2008c; Vourvahis et al., 2014). The $K$ p scalar value of 1.7 was needed to recover in vivo observed plasma concentration-time profiles. Permeabilitylimiting disposition was considered for liver. Intrinsic active uptake clearance and passive diffusion across the sinusoidal membrane and intrinsic efflux clearance on the canalicular membrane, obtained from SCHH studies, were used to capture hepatobiliary disposition. The active hepatic uptake clearance was attributed to OATP1B1-mediated transport based on our presented data (see Results). On the other hand, P-gp was assumed to impact the MVC absorption/canalicular efflux (Walker et al., 2005). Intrinsic metabolic clearance of MVC was obtained using substrate depletion in HLM incubations (Tseng et al., 2018). The model with these initial input parameters (transport-metabolism interplay) resulted in underprediction of hepatic clearance. Therefore, an empirical scaling factor for the hepatic sinusoidal active uptake of 10 (estimated by top-down model fitting of the intravenous data) was applied. This scaling factor for the hepatic sinusoidal active uptake is in line with our previously reported value (Varma et al., 2014). To simulate the effect of inhibitors and inducers on the MVC pharmacokinetic profile, the models for ketoconazole, efavirenz, rifampicin, and ritonavir were adopted directly from the default compound library with certain modifications. The P-gp inhibition constant $\left(K_{\mathrm{i}}\right)$ of $0.4 \mu \mathrm{M}$ was added to the ketoconazole model. The $K_{\mathrm{i}, \mathrm{P} \text {-gp }}$ value for ritonavir was also modified to $0.4 \mu \mathrm{M}$, instead of a default value of $0.03 \mu \mathrm{M}$, which is significantly lower than the reported $\mathrm{IC}_{50, \mathrm{P} \text {-gp }}$ range from 1.5 to $28 \mu \mathrm{M}$ in Caco-2 cells (Gnoth et al., 2011; Kishimoto et al., 2014). In terms of $\mathrm{P}$-gp induction in gut, rifampicin was assumed to increase intestinal P-gp abundances. Intestinal P-gp expression levels were shown to increase by about 3.5-fold following multiple-dose rifampin treatment, which is similar to the increase in the intestinal CYP3A4 level of 4.4-fold (Greiner et al., 1999). Therefore, the intestinal P-gp maximum transport rate $\left(J_{\max }\right)$ value of MVC was assumed to be 3.5 -fold higher when simulating multiple-dose rifampicin interactions. The $K_{\mathrm{i}, \mathrm{OATP} 1 \mathrm{~B} 1}, \mathrm{CYP} 3 \mathrm{~A} 4 E_{\mathrm{max}}$, and CYP3A4 $\mathrm{EC}_{50}$ values of rifampicin were obtained from a previous report to consider the impact of rifampicin on CYP3A4 (both inhibition and induction) as well as inhibition of OATP1B1 at a concomitant dose with MVC and rifampicin (Varma et al., 2013).

TVR and $R$-Diastereomer PBPK Model Development. The physicochemical and pharmacokinetic parameters of TVR and its $R$-diastereomer [VRT-127394 (M0)] used in the present PBPK model are summarized in Table 1. The observed mean pharmacokinetic data of TVR and M0 in healthy subjects receiving a $750 \mathrm{mg}$ oral single dose and multiple doses were used to refine the input parameters for absorption, distribution, and elimination [INCIVEK (telaprevir); https://www.accessdata.fda.gov/drugsatfda_docs/nda/2011/ 201917Orig1s000TOC.cfm]. The absorption of TVR was described with the firstorder model and distribution was described using the minimal PBPK distribution model. The formation of M0 was assumed as a result of TVR metabolism generated by the non-CYP3A pathway. The distribution of M0 was described with a minimal PBPK model, and the clearance was assumed to be driven by further metabolism. The following interaction parameters of TVR were used; $K_{\mathrm{i}, \mathrm{CYP} 3 \mathrm{~A}}$ for testosterone $(18.6 \mu \mathrm{M}), K_{\mathrm{I}, \mathrm{CYP} 3 \mathrm{~A}}$, and $k_{\text {inact,CYP3A }}$ in hepatocytes (see Results), $K_{\mathrm{i}, \mathrm{P}-\mathrm{gp}}(0.48 \mu \mathrm{M})$, and $K_{\mathrm{i}, \mathrm{OATP} 1 \mathrm{~B} 1}(0.11 \mu \mathrm{M})$. To verify the TVR model and determine the in vivo $K_{\mathrm{i}}$ values based on clinical DDI data, default compound files of midazolam and digoxin were used as is, and the atorvastatin PBPK model was adopted from a published report (Zhang, 2015). The performance of the PBPK model predictions was evaluated by the ratio of predicted and observed values ( $R_{\text {pred/obs }}$ ). For $R_{\text {pred/obs }}$, a value between 0.8 and 1.25 was used to assess model performance.

\section{Results}

In Vitro Transport of MVC. The time-course profiles of MVC uptake in SCHH and suspended hepatocytes are shown in Fig. 1. MVC showed temperature-dependent uptake in both systems with $\sim 95 \%$ reduction in uptake at $4^{\circ} \mathrm{C}$ compared with $37^{\circ} \mathrm{C}$, implying active transport. In contrast, 30 and $100 \mu \mathrm{M}$ rifamycin SV enhanced MVC accumulation in SCHH. Significant biliary excretion was noted in $\mathrm{SCHH}$ when incubated with and without $\mathrm{Ca}^{2+} / \mathrm{Mg}^{2+}$. Overall, the results of in vitro studies employing $\mathrm{SCHH}$ suggested active uptake and biliary excretion of MVC. Additionally, temperature-dependent transport was also noted in suspended human hepatocytes. In the uptake studies using transporter-transfected HEK293 cells, MVC was transported by OATP1B1, but not by OATP1B3 and OATP2B1 (Table 2). Moreover, OATP1B1-specific uptake displayed concentration dependency with a biphasic saturation profile (Fig. 2A). Within the concentration range of 2.0-31.2 $\mu \mathrm{M}$, MVC transport conformed to Michaelis-Menten kinetics and was characterized by a $K_{\mathrm{m}}$ value of $5 \mu \mathrm{M}$ and $V_{\max }$ value of $6.25 \mathrm{pmol} / \mathrm{min}$ per milligram (Fig. 2B). The former is lower than the $K_{\mathrm{m}}$ value $(34 \mu \mathrm{M})$ reported using OATP1B1-transfected oocytes (Siccardi et al., 2010). Similar to the stimulatory effect of rifamycin SV noted in SCHH, OATP1B1-mediated uptake of MVC also increased with $100 \mu \mathrm{M}$ rifamycin SV in transfected HEK293 cells; on the other hand, MVC uptake was inhibited by $100 \mu \mathrm{M}$ TVR (Fig. 2C).

In Vitro CYP3A TDI of TVR. The TDI kinetic parameters of TVR for CYP3A were determined with HLM and human hepatocytes using midazolam as a CYP3A probe substrate (Fig. 3; Supplemental Fig. 1). The estimated $K_{\mathrm{I}}$ and $k_{\text {inact }}$ values in HLM were $0.644 \mu \mathrm{M}$ and 0.108 minute $^{-1}$, respectively. These values are close to those previously reported by two independent studies: $1.5 \mu \mathrm{M}$ and 0.065 minute $^{-1}$ and $0.511 \mu \mathrm{M}$ and 0.113 minute $^{-1}$, respectively [INCIVEK (telaprevir); https://www.accessdata.fda.gov/drugsatfda_docs/ nda/2011/201917Orig201911s201000ClinPharmR.pdf] (Oda and Yamano, 2014). The TDI kinetic parameters obtained with human hepatocytes were determined to be a $K_{\mathrm{I}}$ value of $2.24 \mu \mathrm{M}$ and $k_{\text {inact }}$ value of 0.0112 minute $^{-1}$. Thus, the $K_{\mathrm{I}}$ value in human hepatocytes is approximately 3.5 -fold higher versus HLM, whereas the $k_{\text {inact }}$ value in human hepatocytes is approximately 10 -fold lower than that obtained with HLM, resulting in the 33.6-fold difference in the inactivation efficiency $\left(k_{\text {inact }} / K_{\mathrm{I}}\right)$ between the two systems. The $K_{\mathrm{I}}$ and $k_{\text {inact }}$ values obtained with human hepatocytes were 
TABLE 1

Summary of input parameters for PBPK models of MVC, TVR, and M0

\begin{tabular}{|c|c|c|c|c|c|c|}
\hline \multirow{2}{*}{ Parameter (U) } & \multicolumn{2}{|c|}{ MVC } & \multicolumn{2}{|c|}{ TVR ( $S$-configuration) } & \multicolumn{2}{|c|}{ M0 ( $R$-diastereomer) } \\
\hline & Input Value & Source/Comment & Input Value & Source/Comment & Input Value & Source/Comment \\
\hline \multicolumn{7}{|l|}{ Physicochemical property } \\
\hline Molecular weight $(\mathrm{g} / \mathrm{mol})$ & 513.7 & Hyland et al. (2008) & 679.85 & INCIVEK (telaprevir) & 679.85 & Same as TVR \\
\hline $\log \mathrm{P}$ & 2.4 & Hyland et al. (2008) & 4 & INCIVEK (telaprevir) & 4 & Same as TVR \\
\hline Compound type & Monoprotic basic & Hyland et al. (2008) & Neutral & INCIVEK (telaprevir) & Neutral & Same as TVR \\
\hline $\mathrm{p} K_{\mathrm{a}}$ & 7.3 & Hyland et al. (2008) & & & & \\
\hline Plasma fraction unbound & 0.25 & Hyland et al. (2008) & 0.41 & INCIVEK (telaprevir) & 0.41 & Same as TVR \\
\hline Blood/plasma ratio & 0.59 & Hyland et al. (2008) & 0.65 & INCIVEK (telaprevir) & 0.65 & Same as TVR \\
\hline \multicolumn{7}{|l|}{ Absorption } \\
\hline Absorption type & $\mathrm{ADAM}^{a}$ & & First order & & - & \\
\hline Caco-2 permeability $\left(\times 10^{-6} \mathrm{~cm} / \mathrm{s}\right)$ & 2.7 & Measured & - & & - & \\
\hline $\begin{array}{l}\text { Permeability calibrator, propranolol } \\
\quad\left(\times 10^{-6} \mathrm{~cm} / \mathrm{s}\right)\end{array}$ & 23 & Measured & - & & - & \\
\hline $\begin{array}{l}\text { First-order absorption arte constant } \\
(1 / \mathrm{h})\end{array}$ & - & & 0.8 & $\begin{array}{l}\text { Optimized according } \\
\text { to clinical data }\end{array}$ & - & \\
\hline Lag time $(\mathrm{h})$ & - & & 2 & $\begin{array}{l}\text { Optimized according } \\
\text { to clinical data }\end{array}$ & - & \\
\hline Unbound fraction in gut & 0.72 & Assumed & 1 & $\begin{array}{l}\text { Optimized according } \\
\text { to clinical data }\end{array}$ & 1 & Same as TVR \\
\hline Nominal flow in gut model $(1 / \mathrm{h})$ & - & & 10 & $\begin{array}{l}\text { Optimized according } \\
\text { to clinical data }\end{array}$ & - & \\
\hline \multicolumn{7}{|l|}{ Distribution } \\
\hline Distribution model & Full PBPK & Method 2 & Minimal PBPK & & Minimal PBPK & Same as TVR \\
\hline Predicted $V_{\mathrm{dss}}(1 / \mathrm{kg})$ & 2.5 & Hyland et al. (2008) & 2 & $\begin{array}{l}\text { Optimized according } \\
\text { to clinical data }\end{array}$ & 2 & Same as TVR \\
\hline$K_{\mathrm{p}}$ scalar & 1.7 & $\begin{array}{l}\text { Adjusted to recover } \\
\text { observed } V_{\text {dss }}\end{array}$ & - & & - & \\
\hline \multicolumn{7}{|l|}{ Elimination } \\
\hline $\begin{array}{l}\text { CYP3A4/5 } \mathrm{CL}_{\text {int,met }} \\
\text { (ml/min per picomoles) }\end{array}$ & 44.6 & Tseng et al. (2018) & 0.249 & $\begin{array}{l}\text { Optimized according } \\
\text { to clinical data }\end{array}$ & - & \\
\hline $\begin{array}{l}\text { Another } \mathrm{CL}_{\text {int,met }} \\
(\mathrm{ml} / \mathrm{min} \text { per picomoles })\end{array}$ & - & & 0.536 & $\begin{array}{l}\text { Optimized according } \\
\text { to clinical data }\end{array}$ & - & \\
\hline $\mathrm{CL}_{\text {int,HLM }}$ & - & & - & - & 33 & $\begin{array}{l}\text { Optimized according } \\
\text { to clinical data }\end{array}$ \\
\hline Microsomal protein binding & 0.72 & Hyland et al. (2008) & 1 & Assumed & 1 & Assumed \\
\hline Renal CL (1/h) & 12 & Hyland et al. (2008) & - & & - & \\
\hline Enterohepatic circulation (\%) & 100 & Assumed & - & & - & \\
\hline \multicolumn{7}{|l|}{ Transport (intestine) } \\
\hline$K_{\mathrm{m} \text { P-gp }}(\mu \mathrm{M})$ & 37 & Walker et al. (2005) & - & & - & \\
\hline$J_{\max , \mathrm{P}-\mathrm{gp}}(\mathrm{pmol} / \mathrm{min})$ & 104 & Measured & - & & - & \\
\hline Scaling factor & 5 & $\begin{array}{l}\text { Optimized based on } \\
\text { oral PK }\end{array}$ & - & & - & \\
\hline \multicolumn{7}{|l|}{ Transport (liver) } \\
\hline $\mathrm{PS}_{\mathrm{pd}}\left(\mathrm{ml} / \mathrm{min}\right.$ per $10^{6}$ cells $)$ & 0.02 & Measured & - & & - & \\
\hline $\mathrm{CL}_{\text {int, OATP1B1 }}\left(\mu \mathrm{l} / \mathrm{m}\right.$ per $\left.10^{6}\right)$ & 3.96 & Measured & - & & - & \\
\hline Scaling factor & 10 & $\begin{array}{l}\text { Kimoto et al. } \\
\text { (2017) }\end{array}$ & - & & - & \\
\hline $\mathrm{CL}_{\text {int, bile (P-gp) }}\left(\mu \mathrm{l} / \mathrm{m}\right.$ per $\left.10^{6}\right)$ & 2.4 & Measured & - & & - & \\
\hline \multicolumn{7}{|l|}{ Interaction (enzymes) } \\
\hline CYP3A4 $\mathrm{K}_{\mathrm{i}}(\mu \mathrm{M})$ & - & & 18.6 & INCIVEK (telaprevir) & 5.18 & INCIVEK (telaprevir) \\
\hline CYP3A4 K $(\mu \mathrm{M})$ & - & & 2.24 & Measured & - & - \\
\hline CYP3A4 k inact $(1 / \mathrm{h})$ & - & & 0.672 & Measured & - & - \\
\hline \multicolumn{7}{|l|}{ Interaction (transporters) } \\
\hline P-gp $K_{i}(\mu \mathrm{M})$ & - & & $0.48^{b}$ & Optimized & $0.48^{b}$ & Same as TVR \\
\hline OATP1B1 $\mathrm{K}_{\mathrm{i}}(\mu \mathrm{M})$ & - & & $0.11^{c}$ & Optimized & $0.11^{c}$ & Same as TVR \\
\hline
\end{tabular}

ADAM, advanced dissolution, absorption, and metabolism; CL, clearance; $V_{\mathrm{dss}}$, volume of distribution at steady state; $\mathrm{J}_{\text {max }}$, maximum transport rate; $\mathrm{PS}$ pd , passive diffusion clearance; -, not applicable.

${ }^{a}$ Colonic absorption of MVC was assumed to be negligible (regional permeability of colon set as $0.01 \times 10^{-4} \mathrm{~cm} / \mathrm{s}$ ).

${ }^{b}$ The $K_{\mathrm{i}}$ value on P-gp was optimized to recover the TVR interactions with digoxin. This value is 10-fold lower than in vitro $\mathrm{K}_{\mathrm{i}}(4.8 \mu \mathrm{M})$ (Fujita et al., 2013).

${ }^{c} \mathrm{~K}_{\mathrm{i}}$ value on OATP1B1 was optimized to recover the TVR interactions with atorvastatin. This value is about 10 -fold lower than the in vitro $K_{\mathrm{i}}\left(K_{\mathrm{i}}=\mathrm{IC} \mathrm{I}_{50} / 2=1.1 \mu \mathrm{M}\right)(\mathrm{Kunze}$ et al., 2012$)$.

used for DDI prediction and were compared with predictions based on HLM-derived parameters.

PBPK Modeling and Simulations of MVC. A PBPK model for MVC, incorporating transporter function for P-gp and OATP1B1, was developed. The simulated MVC plasma concentration-time profiles and pharmacokinetic parameters were in good agreement with the observed clinical data (Supplemental Fig. 2A; Table 3). Also, the predicted MVC bioavailability (F) of $\sim 17 \%$ - estimated based on the simulated the AUC extrapolated to infinity following intravenous $(30 \mathrm{mg})$ and oral
(100 mg) doses-agreed with the clinical observation of $\sim 23 \%$ at the same oral dose. The fraction of the dose absorbed from gastrointestinal tract $\times$ fraction of the dose that escapes intestinal first-pass metabolism was calculated to be 0.44 , which is an underprediction with the observed fraction of the dose absorbed $\times$ fraction of the dose that escapes intestinal first-pass metabolism of 0.71 estimated from the clinical pharmacokinetics. This difference might be due to notable variability in pharmacokinetics across studies. The MVC model predicted the fractions of dose eliminated via renal and hepatic clearance as 0.3 and 

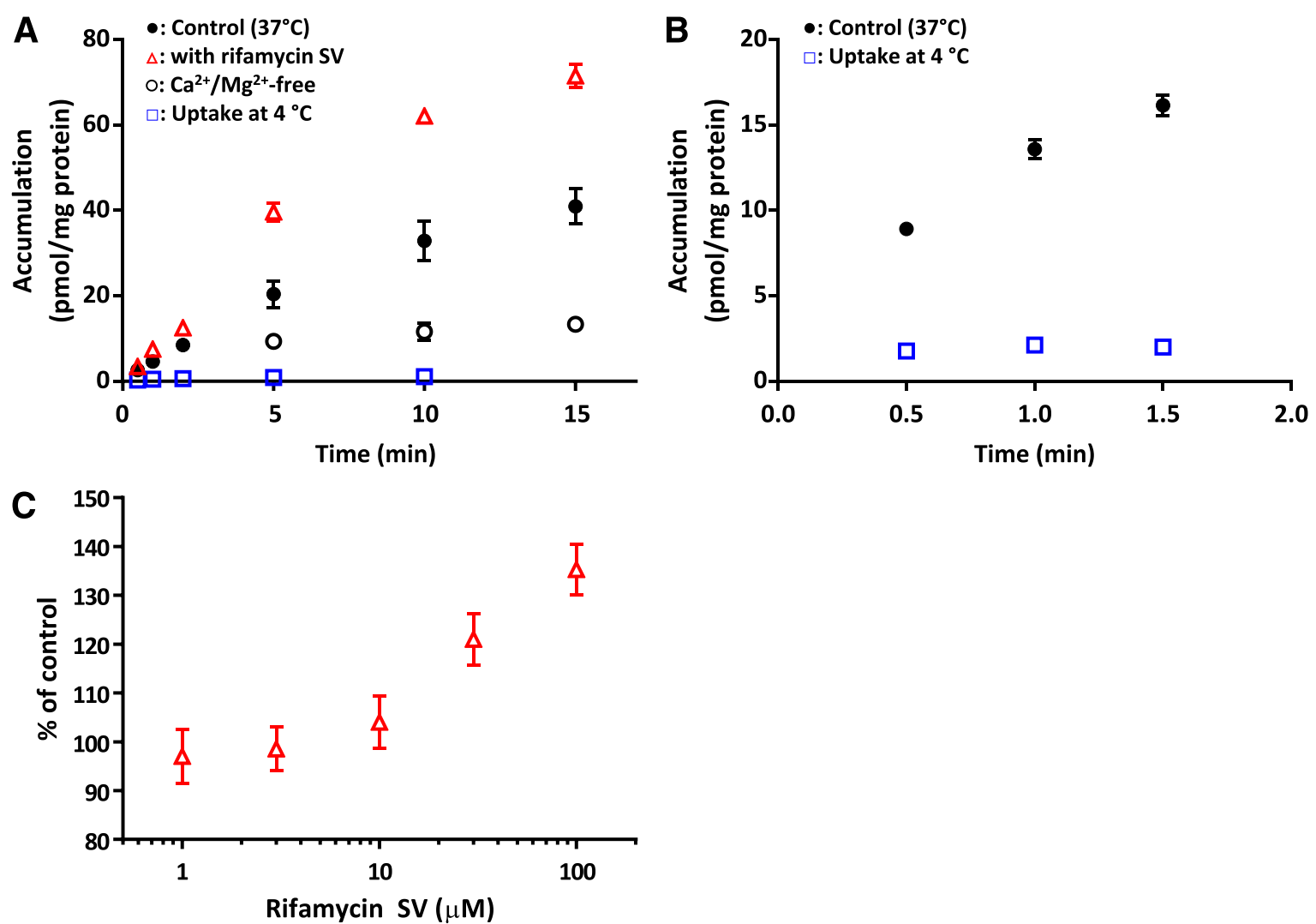

Fig. 1. Hepatic transport of MVC measured using SCHH and suspended human hepatocytes. The time course of MVC uptake by SCHH (A) and hepatocyte suspension (B) was investigated at $1 \mu \mathrm{M}$ at $37^{\circ} \mathrm{C}(\bullet)$ or $4^{\circ} \mathrm{C}(\square)$ with standard HBSS in the presence or absence of $100 \mu \mathrm{M}$ rifamycin SV $(\triangle)$ or $\mathrm{Ca}^{2+} / \mathrm{Mg}^{2+}$-free $\mathrm{HBSS}(\mathrm{O})$. Each point represents the mean \pm S.D. of 4-12 measurements from one to three studies (A) and triplicate from one study (B). Effect of rifamycin SV on MVC uptake (1 $\mu$ M) in SCHH (C) was investigated at $37^{\circ} \mathrm{C}$ for 5 minutes in the presence or absence of rifamycin SV at $1,3,10,30$, and $100 \mu \mathrm{M}$. Each point represents the mean \pm S.D. $(n=4)$ from one study.

0.7 , respectively, which are in line with a clinical mass balance study ( 0.25 of renal clearance and 0.75 of hepatic clearance) (Abel et al., 2008c). The model was further used to quantitatively evaluate the observed clinical DDI between MVC and inhibitors/inducers.

Determination of the $K_{\mathrm{i}}$ Value of TVR for Transporters. A PBPK model for TVR including its $R$-diastereomer, M0, was developed using physicochemical and in vitro parameters. The simulated TVR plasma concentration-time profiles and pharmacokinetic parameters were in good agreement with the observed clinical data (Supplemental Fig. 2B; Table 3). The in vivo $K_{\mathrm{i}}$ values for CYP3A, P-gp, and OATP1B1 were determined based on clinical DDI data obtained with the corresponding probe substrates midazolam (CYP3A), digoxin (P-gp), and atorvastatin

\section{TABLE 2}

Uptake of MVC, pravastatin, rosuvastatin, and propranolol by OATPs in transfected HEK293 cells

The values are presented as uptake ratio (uptake by transfected cells over uptake by wild-type cells). The positive control substrates (pravastatin and rosuvastatin) and negative control (propranolol) exhibited uptake ratios of OATPs within the expected ranges. The uptake study was conducted with a substrate for $3 \mathrm{~min}$. The values represent the mean \pm S.D. $(\mathrm{n}=3)$.

\begin{tabular}{lcccc}
\hline \multirow{2}{*}{ Compound } & Concentration & \multicolumn{3}{c}{ Uptake Ratio } \\
\cline { 3 - 5 } & & OATP1B1 & OATP1B3 & OATP2B1 \\
\hline \multirow{2}{*}{ MVC } & $\mu M$ & & & \\
& 0.1 & $3.1 \pm 0.1$ & $1.3 \pm 0.1$ & $1.2 \pm 0.1$ \\
& 1 & $2.5 \pm 0.1$ & $1.1 \pm 0.0$ & $1.0 \pm 0.0$ \\
Pravastatin & 10 & $2.2 \pm 0.1$ & $0.82 \pm 0.02$ & $0.81 \pm 0.02$ \\
Rosuvastatin & 1 & $64 \pm 2$ & $23 \pm 1$ & $2.1 \pm 0.4$ \\
Propranolol & 1 & $95 \pm 10$ & $31 \pm 2$ & $19 \pm 1$ \\
& 1 & $1.0 \pm 0.1$ & $0.64 \pm 0.03$ & $0.91 \pm 0.04$ \\
\hline
\end{tabular}

(CYP3A and OATP1B1). The predicted AUC ratios (AUCRs) of these substrates are summarized in Table 4. The HLM-derived TDI parameters for TVR overpredicted (3.4- to 3.7-fold) the AUCRs of midazolam compared with the clinically observed AUCR. In contrast, the human hepatocyte-based TDI parameters rendered improved predictions of the midazolam AUCR (i.e., $R_{\text {pred/obs }}$ value of $1.1-1.3$ ), in which the model performance was within the range, except for the atorvastatin-TVR DDI. The in vivo $K_{\mathrm{i}}$ values for P-gp and OATP1B1 inhibition needed to recover the TVR interactions with digoxin and atorvastatin were about 10-fold lower than the reported $\mathrm{IC}_{50}$ values (4.8 and $1.1 \mu \mathrm{M}$, respectively) obtained in vitro (Kunze et al., 2012; Fujita et al., 2013). The same in vivo $K_{\mathrm{i}}$ values for P-gp and OATP1B1 were assumed for M0.

DDI Prediction of MVC. The predicted MVC plasma exposure changes (AUC) in the presence of several inhibitors or inducers are summarized in Table 5. An increase in MVC exposure with TVR can be well recovered by considering CYP3A and transporter (P-gp and OATP1B1) inhibition using the in vivo $K_{\mathrm{i}}$ values for TVR (Fig. 4A). Based on the sensitivity analysis, use of the in vitro $K_{\mathrm{i}}$ values for P-gp and OATP1B1 resulted in a predicted AUCR of $\sim 5$; however, the optimized $K_{\mathrm{i}}$ values (estimated via PBPK modeling of probe substrates) recovered the MVC AUCR well (Supplemental Fig. 3).

Further sensitivity analysis of the MVC-TVR interaction (AUCR and $C_{\max }$ ratio) indicated that inhibition of P-gp, CYP3A, or OATP1B1 alone results in about a 2-fold increase, and inhibition of CYP3A and either transporter results in a $\sim 4$ - to 5-fold increase, while inhibition of all three mechanisms (P-gp, CYP3A, and OATP1B1) yields about an 8-fold increase in the AUCR (Fig. 4, B and C). Ketoconazole, a CYP3A inhibitor, and ritonavir, a CYP3A inhibitor and inducer, were predicted 

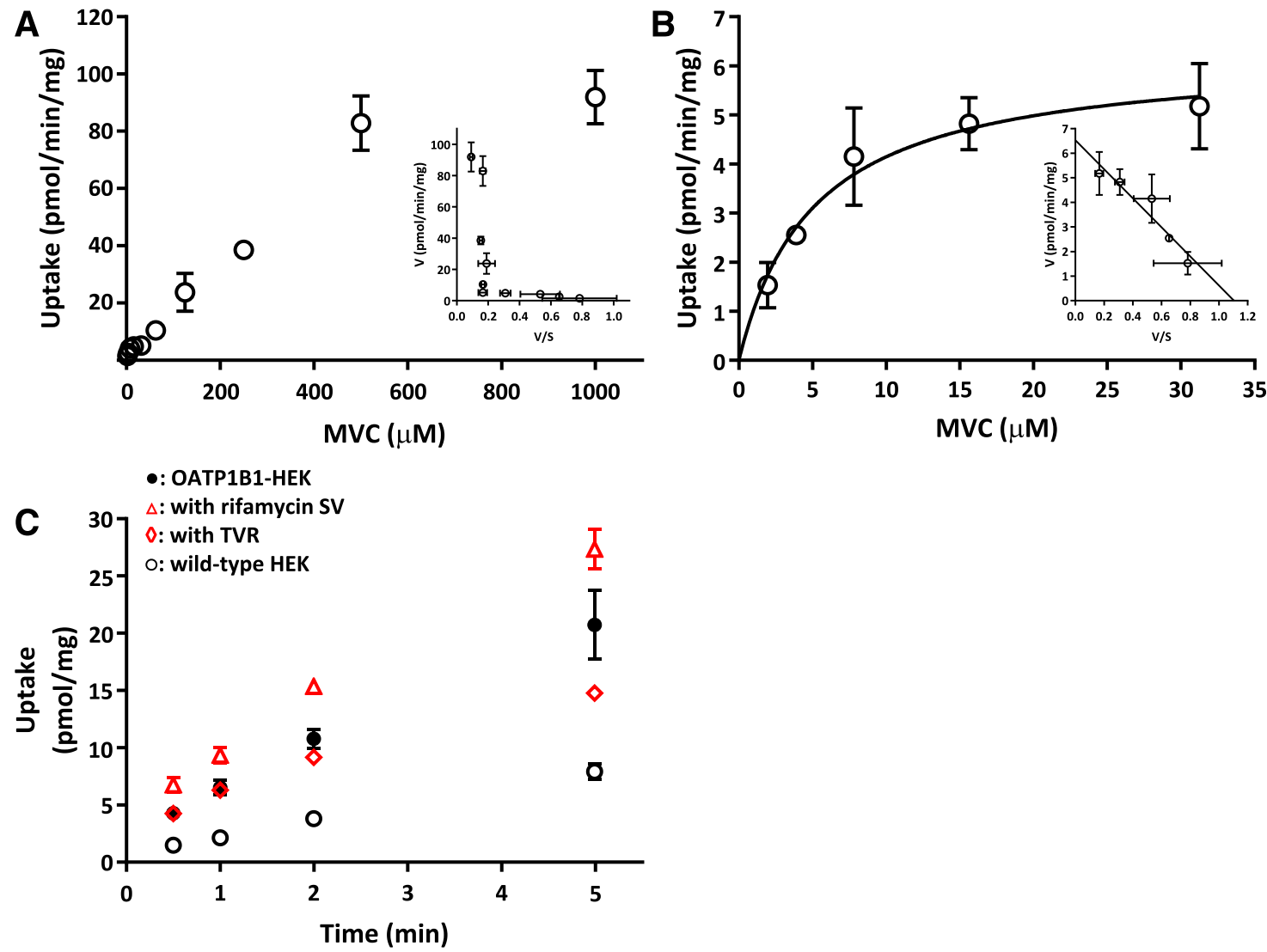

Fig. 2. OATP1B1-mediated uptake of MVC measured in transfected HEK293 cells. Uptake rate was measured at a MVC concentration range of 1.95-1000 $\mu \mathrm{M}$ (A) and low $K_{\mathrm{m}}$ was determined in the range of $1.95-31 \mu \mathrm{M}(\mathrm{B})$ at $37^{\circ} \mathrm{C}$. The inset shows an Eadie-Hofstee plot of MVC uptake. The accumulation of MVC $(1 \mu \mathrm{M})$ was investigated at $37^{\circ} \mathrm{C}$ in the presence or absence of $100 \mu \mathrm{M}$ rifamycin SV or $100 \mu \mathrm{M}$ TVR $(\mathrm{C})$. In (C), data points represent the observed data in OATP1B1-HEK without rifamycin SV $(\bullet)$, with rifamycin SV $(\triangle)$ or TVR $(\diamond)$, and wild-type HEK $(\bigcirc)$. Each point represents the mean \pm S.D. $(n=3-6)$ from one study.

to cause an increase in MVC exposure when incorporating P-gp inhibition, while efavirenz and rifampicin, which are inducers of CYP3A, were predicted to reduce the MVC AUCR. When MVC DDIs were predicted by using default models of ketoconazole and ritonavir, which meant the $K_{\mathrm{i}, \mathrm{P} \text {-gp }}$ value of ketoconazole was not included and that of ritonavir was 0.03 , the AUCR with ketoconazole was underpredicted and that with ritonavir was overpredicted $\left(R_{\text {pred/obs }}\right.$ value of 0.53 and 1.6, respectively). The reported $\mathrm{P}-\mathrm{gp} \mathrm{IC}_{50}$ ranges of ketoconazole and ritonavir using Caco- 2 cells were approximately

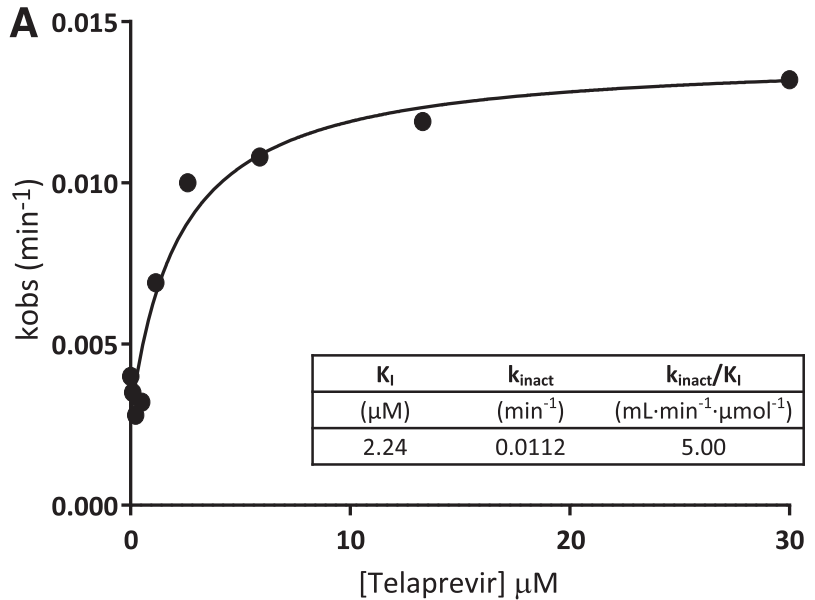

0.24-3.4 and 1.5-28 $\mu \mathrm{M}$, respectively (Gnoth et al., 2011; Kishimoto et al., 2014; Mikkaichi et al., 2014). Therefore, the prediction of the AUCR using the $K_{\mathrm{i}, \mathrm{P} \text {-gp }}$ value of ketoconazole and ritonavir set at $0.4 \mu \mathrm{M}$, improved the $R_{\text {pred/obs }}$ values to 0.81 and 1.1 , respectively. The MVC DDI with rifampicin was also predicted using a PBPK model assuming an increased intestinal P-gp $J_{\max }$ value (i.e., a 4-fold increase corresponding to the P-gp expression change in intestine on rifampicin treatment) and OATP1B1 inhibition. Accounting for intestinal P-gp induction along with hepatic OATP1B1 inhibition

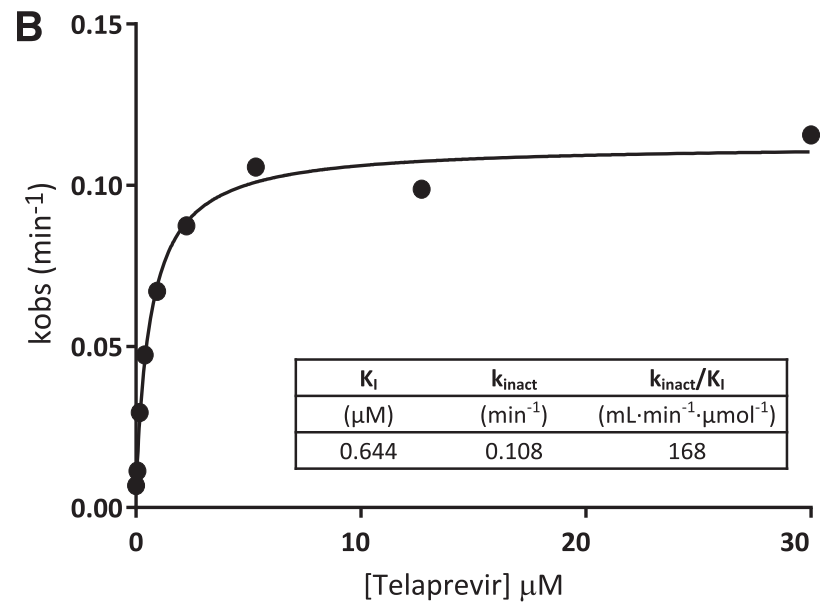

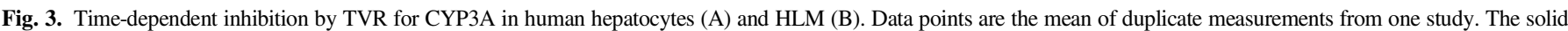

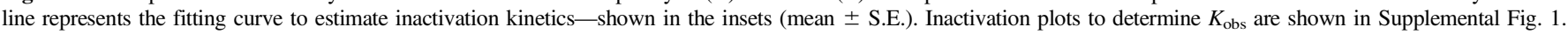


TABLE 3

PBPK model predictions of MVC pharmacokinetics

\begin{tabular}{|c|c|c|c|c|c|c|}
\hline Dose & Monitored & PK Parameter & Predicted & Observed & $R_{\text {pred/obs }}$ & References for Observed \\
\hline \multicolumn{7}{|l|}{ MVC } \\
\hline \multirow[t]{2}{*}{ Intravenous $3 \mathrm{mg}$} & \multirow[t]{2}{*}{ MVC } & $\mathrm{AUC}_{t}(\mathrm{ng} / \mathrm{ml}$ per hour $)$ & 58.2 & 57.6 & 1.0 & \multirow[t]{2}{*}{ Abel et al. (2008c) } \\
\hline & & $C_{\max }(\mathrm{ng} / \mathrm{ml})$ & 34.3 & 36.9 & 0.94 & \\
\hline \multirow{2}{*}{ Intravenous $10 \mathrm{mg}$} & \multirow{2}{*}{ MVC } & $C_{\max }(\mathrm{ng} / \mathrm{ml})$ & 114 & 122 & 0.93 & \multirow{2}{*}{ Abel et al. (2008c) } \\
\hline & & $\mathrm{CL}(\mathrm{l} / \mathrm{h})$ & 42.5 & $\mathrm{NC}$ & - & \\
\hline Intravenous $30 \mathrm{mg}$ & MVC & $\mathrm{AUC}_{t}(\mathrm{ng} / \mathrm{ml}$ per hour$)$ & 706 & 670 & 1.1 & Abel et al. (2008c) \\
\hline \multirow[t]{5}{*}{ Oral 150 mg (twice a day) } & \multirow[t]{5}{*}{ MVC } & $\mathrm{AUC}_{t}$ or $\mathrm{AUC}_{\mathrm{inf}}(\mathrm{ng} / \mathrm{ml}$ per hour $)$ & 542 & 599 & 0.90 & \multirow[t]{5}{*}{ Vourvahis et al. (2014) } \\
\hline & & $C_{\max }(\mathrm{ng} / \mathrm{ml})$ & 103 & 111 & 0.93 & \\
\hline & & $\mathrm{F}(\text { oral } 100 \mathrm{mg})^{a}$ & 0.17 & 0.23 & 0.72 & \\
\hline & & $\mathrm{F}_{\mathrm{a}} \times \mathrm{F}_{\mathrm{g}}{ }^{b}$ & 0.44 & 0.71 & 0.61 & \\
\hline & & $\mathrm{F}_{\mathrm{h}}$ (intravenous $\left.30 \mathrm{mg}\right)^{c}$ & 0.38 & 0.32 & 1.2 & \\
\hline \multicolumn{7}{|c|}{ He } \\
\hline Oral $750 \mathrm{mg}$ single & TVR & $\mathrm{AUC}_{t}(\mathrm{ng} / \mathrm{ml}$ per hour $)$ & 19,421 & $11,102-14,930$ & $1.3-1.7$ & \multirow[t]{5}{*}{ INCIVEK (telaprevir) } \\
\hline \multirow{4}{*}{ Oral $750 \mathrm{mg}$ (three times a day) } & TVR & $T_{\max }(\mathrm{h})$ & 4.0 & $2.7-3.5$ & $1.1-1.5$ & \\
\hline & \multirow[t]{3}{*}{ M0 } & $\mathrm{AUC}_{t}(\mathrm{ng} / \mathrm{ml}$ per hour $)$ & 15,343 & $12,320-14,143$ & $1.1-1.2$ & \\
\hline & & $C_{\max }(\mathrm{ng} / \mathrm{ml})$ & 2099 & 1804-2076 & $1.0-1.2$ & \\
\hline & & $T_{\max }(\mathrm{h})$ & 4.57 & $2.7-4.0$ & $1.1-1.7$ & \\
\hline \multirow[t]{3}{*}{ Oral $750 \mathrm{mg}$ (three times a day) } & \multirow[t]{3}{*}{ TVR } & $\mathrm{AUC}_{t}(\mathrm{ng} / \mathrm{ml}$ per hour $)$ & 20,613 & $20,013-21,980$ & $0.94-1.0$ & \multirow[t]{3}{*}{ Vourvahis et al. (2014) } \\
\hline & & $C_{\max }(\mathrm{ng} / \mathrm{ml})$ & 3236 & $3250-3533$ & $0.92-1.0$ & \\
\hline & & $T_{\max }(\mathrm{h})$ & 4.0 & 4.0 & 1.0 & \\
\hline
\end{tabular}

$\mathrm{AUC}_{\mathrm{inf}}, \mathrm{AUC}$ extrapolated to infinity; $\mathrm{AUC}_{t}$, AUC to the last measurable concentration at time $t$; CL, clearance; $\mathrm{F}$, oral bioavailability; $\mathrm{F}_{\mathrm{a}}$, fraction of the dose absorbed from the gastrointestinal

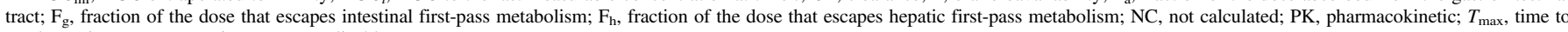
reach maximum concentration; -, not applicable.

${ }^{a}$ The Predicted $\mathrm{F}$ value was calculated by the predicted $\mathrm{AUC}_{\text {inf }}$ intravenous $30 \mathrm{mg}$ and oral $100 \mathrm{mg}$ doses.

${ }^{b}$ The $F_{a} \times F_{g}$ value was calculated from $F$ and intravenous CL (assumed to be hepatic CL), using the following equation: $F=F_{a} \times F_{g} \times F_{h}$.

${ }^{c}$ The $F_{h}$ value was calculated from the hepatic $C L\left(C L_{h}\right)$, using $F_{h}=1-C L_{h} / Q_{h}$; where $Q_{h}$ is the hepatic blood flow. Nonrenal CL $=33.8 \mathrm{l} / \mathrm{h}$ at intravenous $30 \mathrm{mg}$ from reference Abel et al. $(2008 \mathrm{c})$ was used as $\mathrm{CL}_{\mathrm{h}}$.

resulted in a predicted AUCR of 0.37 , which is in line with the observed AUCR of 0.33 .

\section{Discussion}

Our findings from in vitro mechanistic studies along with the comprehensive PBPK modeling and simulations, verified with a range of clinical DDI data, provide evidence for the involvement of CYP3A, $\mathrm{P}-\mathrm{gp}$, and OATP1B1 in determining the pharmacokinetics and drug interactions of MVC (Fig. 5).

We characterized the hepatic transporter-mediated disposition of MVC using transfected HEK293 cells and cryopreserved human primary hepatocytes. The present study provided additional in vitro data in support of OATP substrate activity. First, uptake by OATP1B1transfected (vs. mock-transfected HEK293) cells was evident (uptake ratio of $\sim 3$ ), which exhibited biphasic kinetics (Fig. 2A; Table 2). Second, temperature-dependent uptake of MVC was observed in human hepatocyte systems (Fig. 1, A and B). However, unexpectedly, $100 \mu \mathrm{M}$ rifamycin SV (a pan-OATP inhibitor) stimulated MVC uptake in both OATP1B1-transfected cells and SCHH (Figs. 1, A and C and 2C). Stimulation of uptake for several OATP substrates in the presence of inhibitors is well documented, and may involve mechanisms such as cis and/or trans stimulation and allosterism (Wang et al., 2005; Kimoto et al., 2011; Roth et al., 2011; Wlcek et al., 2013; Varma et al., 2017). Since this phenomenon was observed in both transfected cells and human hepatocytes, potential inhibition of metabolism or basolateral efflux transporters by rifamycin SV can be ruled out. Nevertheless, our studies with transfected cells indicated inhibition of MVC uptake by TVR (Fig. 2C), which has been previously shown to be an OATP inhibitor (Kunze et al., 2012; Chu et al., 2013;

TABLE 4

DDI predictions of probe substrates with TVR

The reference for the observed AUCR was INCIVEK (telaprevir) (https://www.accessdata.fda.gov/drugsatfda_docs/nda/2011/201917Orig201911s201000ClinPharmR.pdf). Simcyp default files for the substrates were used (Sim-Midazolam and SV-Digoxin).

\begin{tabular}{|c|c|c|c|c|c|c|}
\hline DDI with TVR & Elimination in Model & $\begin{array}{l}\text { Predicted AUCR by } \\
\text { HHEP-TDI }\end{array}$ & $\begin{array}{c}\text { Predicted AUCR by } \\
\text { HLM-TDI }\end{array}$ & $\begin{array}{l}\text { Observed AUCR } \\
\quad(90 \% \mathrm{CI})\end{array}$ & $\begin{array}{l}R_{\text {pred/obs }} \text { by } \\
\text { HHEP-TDI }\end{array}$ & $\begin{array}{l}R_{\text {pred/obs }} \text { by } \\
\text { HLM-TDI }\end{array}$ \\
\hline Midazolam, intravenous $0.5 \mathrm{mg}$ & CYP3A4, 3A5 & 4.55 & 12.6 & $3.4(3.04,3.79)$ & 1.3 & 3.7 \\
\hline Midazolam, oral $2 \mathrm{mg}$ & CYP3A4, 3A5 & 9.83 & 30.2 & $8.96(7.75,10.4)$ & 1.1 & 3.4 \\
\hline Digoxin, oral $0.5 \mathrm{mg}$ & P-gp (intestine, biliary) & 2.14 & - & $1.85(1.70,2.00)$ & 1.2 & - \\
\hline Atorvastatin, oral $20 \mathrm{mg}$ & $\begin{array}{l}\text { CYP3A (inhibitor, TDI), } \\
\text { OATP1B1, P-gp }\end{array}$ & 14.0 & 29.0 & $7.88(6.84,9.07)$ & 1.8 & 3.7 \\
\hline
\end{tabular}

CI, confidence interval; HHEP, human hepatocytes; -, not applicable. 
TABLE 5

DDI predictions of MVC with inhibitors and inducers

Simcyp default files for inhibitors were used (Sim-Ketoconazole-400 mg QD, SV-Ritonavir, SV-Efavirenz, and SV-Rifampicin-MD).

\begin{tabular}{|c|c|c|c|c|c|}
\hline MVC DDI with & Interactions in Model & Predicted AUCR & Observed AUCR (90\% CI) & $R_{\text {pred/obs }}$ & References for Observed \\
\hline TVR 750 mg (three times a day) & CYP3A (inh, TDI), OATP1B1, P-gp & 7.90 & $9.49(7.94,11.34)$ & 0.83 & Vourvahis et al. (2014) \\
\hline Ketoconazole $450 \mathrm{mg}$ (once a day) & CYP3A (inh), P-gp & 4.04 & $5.01(3.98,6.29)$ & 0.81 & Abel et al. (2008b) \\
\hline Ritonavir $100 \mathrm{mg}$ (twice a day) & CYP3A (TDI, ind), P-gp & 3.10 & $2.61(1.92,3.56)$ & 1.1 & Abel et al. (2008b) \\
\hline Efavirenz $600 \mathrm{mg}$ (once a day) & CYP3A (ind) & 0.71 & $0.49(0.41,0.57)$ & 1.4 & Abel et al. (2008a) \\
\hline 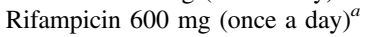 & CYP3A (inh, ind), OATP1B1, P-gp (ind) & 0.37 & $0.33(0.28,0.38)$ & 1.1 & Abel et al. (2008a) \\
\hline
\end{tabular}

$\mathrm{CI}$, confidence interval; ind, induction; inh, inhibition.

${ }^{a}$ The scaling factor for intestinal P-gp $(\times 4)$ was assumed to induce P-gp in gut. The $K_{\mathrm{i}, \mathrm{OATP} 1 \mathrm{~B} 1}, \mathrm{CYP} 3 \mathrm{~A} E_{\max }$, and CYP3A EC $\mathrm{E}_{50}$ values were used from a previous report $($ Varma et al., 2013).

Furihata et al., 2014). It is, therefore, important to consider other experimental conditions (e.g., additional OATP inhibitors and incubation at $4{ }^{\circ} \mathrm{C}$ ) in the process of evaluating the role for hepatic uptake in the clearance of drugs, particularly when stimulation of activity is noted in vitro.
Although the high-resolution structure of OATP1B1 has not been solved, numerous groups have reported that substrates such as estrone3 -sulfate present multiphasic uptake kinetics plausibly due to more than one substrate binding site (Tamai et al., 2001; Noé et al., 2007; Gui and Hagenbuch, 2009). Further evidence for the presence of multiple

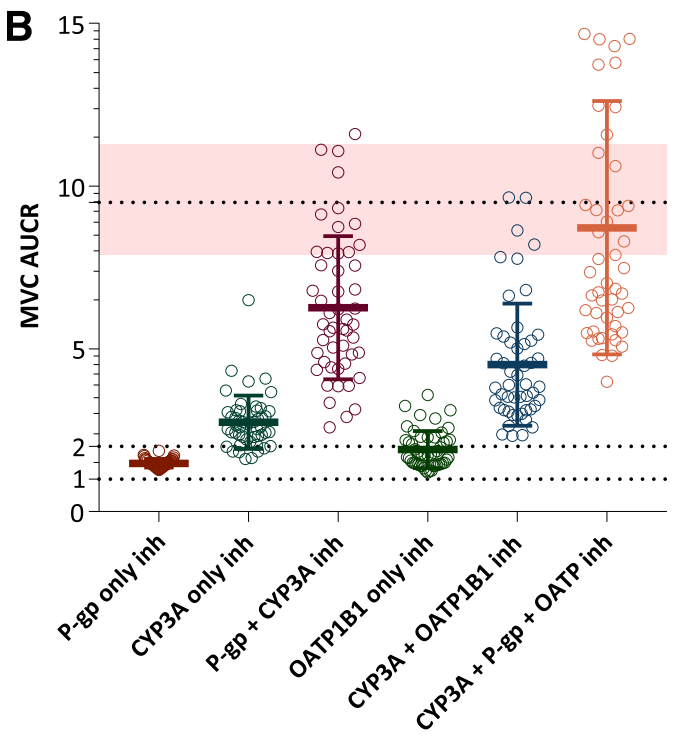

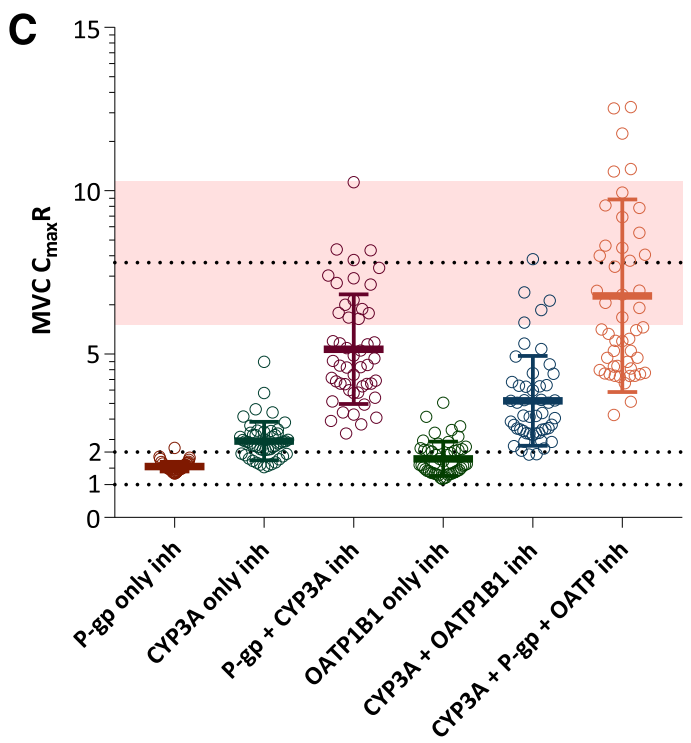

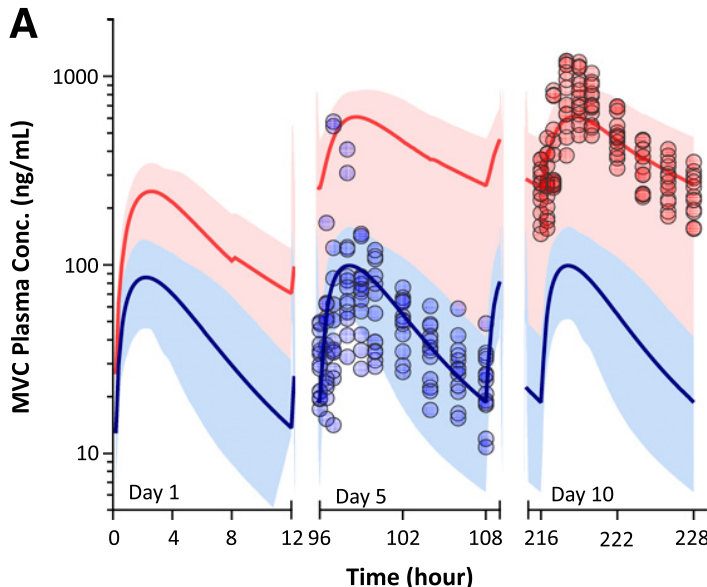

Fig. 4. (A) PBPK model-based prediction of the concentration-time profile of MVC in the presence or absence of TVR. Simulations were based on the dosage regimen used in the clinical study (Vourvahis et al., 2014). In treatment 1, MVC $150 \mathrm{mg}$ (twice a day) was administered for 5 days; and in treatment 2, MVC $150 \mathrm{mg}$ (twice a day) plus TVR $750 \mathrm{mg}$ (three times a day) was administered for 10 days. Solid lines and circles represent simulated and observed data, respectively. Blue and pink shaded areas represent 95\% confidence interval (CI) of MVC simulated plasma concentration when dosed alone or with TVR, respectively. (B and C) Predicted effect of TVR on MVC AUCR and $C_{\max }$ ratio $\left(C_{\max } \mathrm{R}\right)$, assuming P-gp inhibition alone, CYP3A inhibition alone, OATP1B1 inhibition alone, inhibition of both CYP3A and OATP1B1, and inhibition of all mechanisms. Horizontal line with shaded area represents mean and $95 \% \mathrm{CI}$ of observed AUCR or $C_{\max } \mathrm{R}$. In (B and C) circles represent simulated individual values (population size of 50). Lines and error bars denote mean and S.D. 


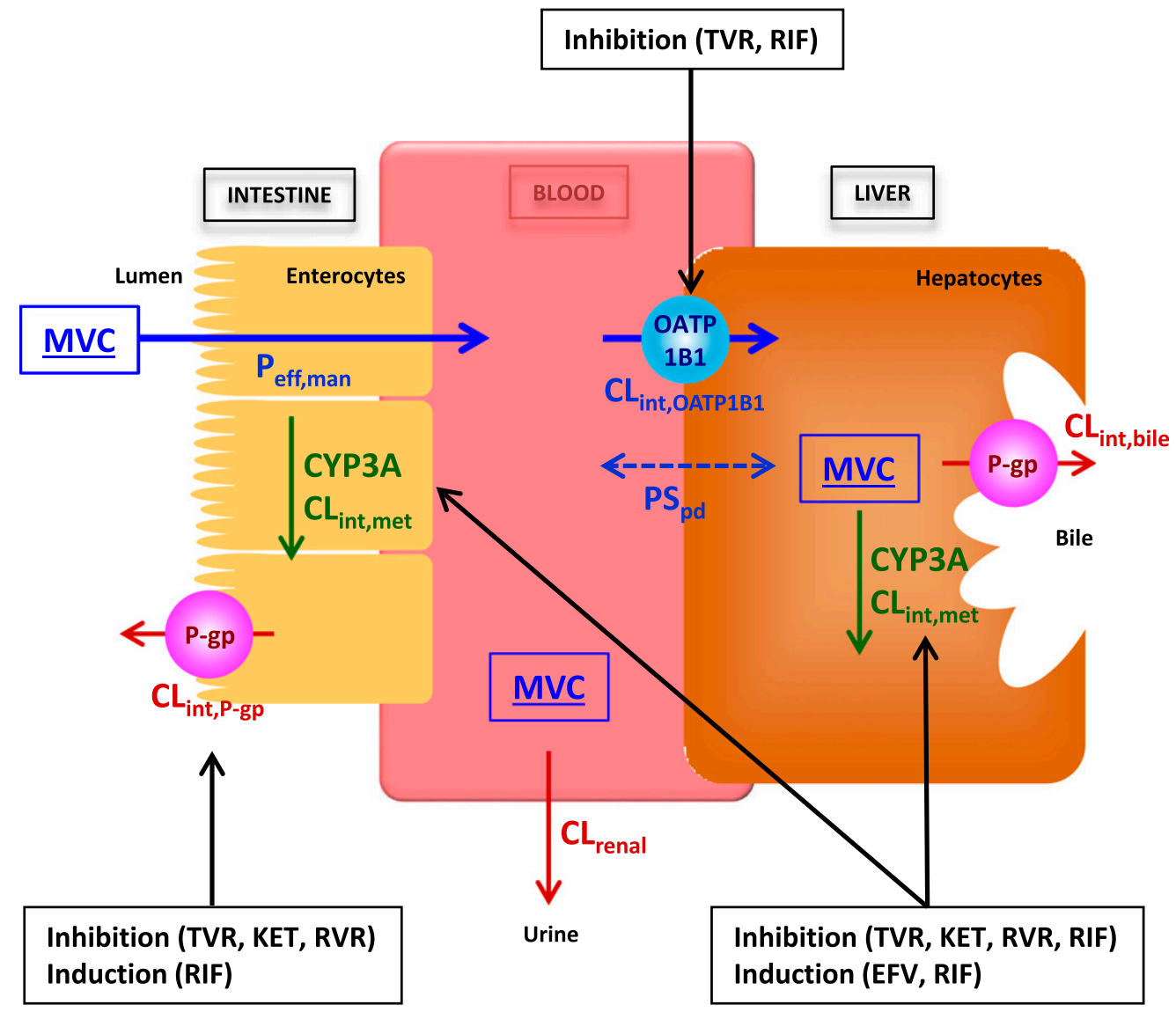

Fig. 5. A schematic of MVC disposition and DDI mechanisms is illustrated. MVC is taken up into hepatocytes across the sinusoidal membrane by passive and active uptake via OATP1B1, and is subjected to efflux into bile across the canalicular membrane via P-gp. MVC is primarily metabolized by CYP3A in gut and liver. Intestinal P-gp-mediated efflux influences MVC absorption. Renal clearance of MVC is about $23 \%$ of total clearance. EFV, efavirenz; KET, ketoconazole; RIF, rifampicin; RVR, ritonavir.

binding sites comes from the observed stimulation of transport of some substrates by known OATP inhibitors (Wang et al., 2005; Wlcek et al., 2013). Earlier studies using cysteine scanning mutagenesis suggested that a set of common but not identical amino acids on a transmembrane domain 10 of OATP1B1 is involved in the substrate binding sites/ translocation pathways for the different substrates, and that certain translocation pathways are stimulated while others are inhibited by the same inhibitor (Ohnishi et al., 2014). Our in vitro studies showed that: 1) the uptake of MVC was biphasic in the OATP1B1expressed HEK293 cells and 2) there was notable stimulation of MVC uptake by rifamycin SV (Figs. 1, A and C and 2C) and cyclosporin A (data not shown, $160 \%$ of control) but inhibition by TVR (Fig. 2C). Taken together, our results suggest different binding sites on OATP1B1 and that possibly MVC and TVR are competing for the same binding pocket.

The DDI predictions for the CYP3A probe substrate (intravenous and oral midazolam) using TVR TDI parameters obtained from human hepatocytes were in good agreement with the observed data, while those estimated using HLM considerably overpredicted (Table 4). Consistent with our results, certain CYP3A inhibitors were also presented with higher inactivation potency in HLM, and the TDI parameters obtained using human hepatocytes better recovered clinical DDIs (Xu et al., 2009; Chen et al., 2011; Mao et al., 2013, 2016). System-dependent apparent differences in the $K_{\mathrm{I}}$ value may be attributed to the lower intracellular concentrations of the inhibitor at the site of the enzyme (hepatocytes vs. HLM). It should be noted that many of these drugs including TVR are P-gp substrates in vitro and could be subjected to efflux in hepatocytes
[INCIVEK (telaprevir); https://www.accessdata.fda.gov/drugsatfda_docs/ nda/2011/201917Orig201911s201000ClinPharmR.pdf] (White et al., 2010; Weiss et al., 2014). On the other hand, the lower $k_{\text {inact }}$ value in human hepatocytes may be driven by the differences in enzyme expression, sequential metabolism including intermediate complexes, or the concentration of inhibitor and/or metabolite(s) in cells. The estimated inactivation parameters $\left(k_{\text {inact }}\right.$ and $\left.K_{\mathrm{I}}\right)$ in human hepatocytes can be considered as apparent hybrid parameters between the rate of diffusion through the cell membrane, the total metabolic consumption rate (including sequential metabolism), and the intrinsic enzyme inactivation rate. Further mechanistic studies are warranted to understand the notable differences between human hepatocytes and HLM. Nevertheless, the current study suggests that human hepatocytes, which are physiologically relevant and closer to in vivo, should be considered when prospectively modeling DDIs involving TDI of CYP3A.

A full PBPK model was developed for MVC, assuming permeabilitylimited hepatic disposition (OATP1B1-CYP3A interplay) to quantitatively rationalize clinical DDIs of MVC as a victim drug (Fig. 5). A TVR PBPK model including its $R$-diastereomer, M0, was also developed, wherein transporter- and enzyme-based interactions are captured. The hepatocyte-to-plasma unbound ratio of TVR and M0 was assumed to be 1 in the model. M0 was found to be at equivalent levels to TVR in plasma at steady state [INCIVEK (telaprevir); https://www.accessdata.fda.gov/ drugsatfda_docs/nda/2011/201917Orig201911s201000ClinPharmR.pdf]. We, therefore, developed a model for the metabolite and assumed that the inhibitory potency of M0 against P-gp and OATP1B1 is similar to TVR. The inhibition potency of TVR including M0 in the model was 
refined and verified based on its clinical interactions with probe substrates: midazolam for CYP3A, digoxin for P-gp, and atorvastatin for CYP3A, OATP1B1, and P-gp. Collectively, the modeling and simulations suggested that TVR clinical DDIs with probe substrates for CYP3A, P-gp, and OATP1B1 are well described when considering: 1) in vitro CYP3A reversible inhibition of TVR and M0, 2) in vitro $K_{\mathrm{I}}$ and $k_{\text {inact }}$ values of TVR obtained from human hepatocytes, and 3) P-gp and OATP1B1 reversible inhibition by TVR and M0 with $\sim 10$-fold lower (optimized) $K_{\mathrm{i}}$ value than noted in the in vitro inhibition values. Previous studies from our group and others have highlighted the need for transporter $K_{\mathrm{i}}$ values to be lower than those observed in vitro to recover clinical DDIs (Varma et al., 2012; Yoshikado et al., 2016; Shebley et al., 2017; Barnett et al., 2018). The empirical correction of the in vitro transporter $K_{\mathrm{i}}$ value may add some degree of uncertainty to the interpretation of quantitative contribution of the individual mechanisms to the noted DDIs. The potential TDI for transporters, such as cyclosporin A, could be one possibility (Takahashi et al., 2016; Shitara and Sugiyama, 2017). Nevertheless, our crossvalidation approach to verify individual interaction mechanisms of TVR using clinical data from probe substrates (e.g., midazolam for CYP3A, digoxin for P-gp, and atorvastatin for OATP1B1) provided rationale for such empirical corrections to the less understood in vitro-in vivo disconnect in transporter inhibition potency.

Ketoconazole is often used as a CYP3A probe inhibitor in clinical DDI studies; however, it can inhibit intestinal P-gp ( $\mathrm{IC}_{50}$ range of 0.42-3.4 $\mu \mathrm{M}$ ) (Kishimoto et al., 2014; Mikkaichi et al., 2014). In this regard, clinical studies have demonstrated a significant increase in plasma exposure of metabolically stable drugs such as fexofenadine (P-gp substrate) by ketoconazole [fexofenadine hydrochloride (https://www.accessdata.fda.gov/drugsatfda_docs/label/ 2003/20786se8-014,20872se8-011,20625se8-012_allegra_lbl.pdf)]. Moreover, no change was observed in monkeys after intravenous administration of fexofenadine with ketoconazole, while its oral bioavailability increased approximately 2-fold (Ogasawara et al., 2007). Similarly, ritonavir inhibits CYP3A along with P-gp. Clinical evidence implies an increase in plasma exposure of digoxin by ritonavir due to P-gp inhibition (Penzak et al., 2004; Kirby et al., 2012). In line with these observations, PBPK modeling of ketoconazole and ritonavir interactions with probe substrates and $\mathrm{MVC}$ using an in vivo $K_{\mathrm{i}, \mathrm{P} \text {-gp }}$ value of $0.4 \mu \mathrm{M}$ supported the role of $\mathrm{P}$-gp in limiting the intestinal absorption of MVC. Consequently, inhibition of intestinal P-gp likely contributes to the observed strong interaction between MVC and TVR.

Rifampicin induces not only CYP3A but also P-gp at the intestine (Chen and Raymond, 2006). Greiner et al. (1999) reported that oral exposure of digoxin is reduced by about 2 -fold with multidose rifampicin treatment, although intravenous exposure of digoxin is less affected. The same study also showed about 4-fold increase in intestinal P-gp expression levels in the rifampicin-treatment group, suggesting that increased efflux further limited digoxin absorption. Since MVC is a dual substrate for CYP3A and P-gp, the decrease in MVC exposure by rifampicin could be explained by induction of both CYP3A and P-gp in the gut. In addition, a model-based analysis has suggested that a concomitant dose of rifampicin following chronic treatment imposes dual effects of CYP3A induction and OATP1B1 inhibition (Varma et al., 2013). Consistently, PBPK simulations of MVC-rifampicin DDIs were in good agreement with the observed data when assuming 4-fold induction of intestinal P-gp and simultaneous inhibition of OATP1B1-mediated hepatic uptake in addition to CYP3A induction. Efavirenz (a moderate CYP3A inducer) does not induce intestinal P-gp expression in humans (Mouly et al., 2002; Oswald et al., 2012), and is not an OATP1B1 inhibitor at clinically relevant concentrations (Karlgren et al., 2012). Therefore, the MVC-efavirenz interaction could be well described by considering CYP3A induction only. The prediction results of MVC DDIs with ketoconazole, ritonavir, efavirenz, and rifampicin suggested that $\mathrm{MVC}$ oral clearance is determined by not only CYP3A4-mediated metabolism but also by P-gp-mediated intestinal efflux. Overall, this study emphasizes the need to capture intestinal P-gp when rationalizing or prospectively predicting interactions with perpetrator drugs like ketoconazole (CYP3A inhibitor) and rifampicin (CYP3A inducer).

In summary, our in vitro mechanistic studies and PBPK modeling and simulations suggest that: 1) OATP1B1-mediated uptake along with CYP3A determine the hepatic clearance of MVC, and thus contribute to the interaction with TVR; 2) the CYP3A inactivation parameters of TVR from human hepatocytes well predict the clinical interactions with probe substrates; and 3) P-gp-mediated intestinal efflux limits the intestinal absorption of MVC, and drugs such as TVR, ketoconazole, and rifampicin effect its oral exposure by modulating the P-gp function/ expression. Finally, this study presents a comprehensive case example for quantitative deconvolution of multiple mechanisms including complex scenarios, such as transporter-enzyme interplay, metabolite contribution, and combined intestinal-liver disposition often involved in clinical DDIs.

\section{Acknowledgments}

We thank Soraya Eatemadpour for generating the permeability data and Mohammed Ullah, previously at Pfizer, Sandwich, United Kingdom, for conducting the in vitro MVC OATP1B $1 K_{\mathrm{m}}$ study. We also gratefully acknowledge the scientific discussions and input provided by Dr. R. Scott Obach, Dr. Theunis C. Goosen, Dr. Shinji Yamazaki, Dr. Jillian Johnson, and Dr. Gwendolyn D. Fate.

\section{Authorship Contributions}

Participated in research design: Kimoto, Vourvahis, Varma.

Conducted experiments: Kimoto, Scialis, Eng.

Performed data analysis: Kimoto.

Wrote or contributed to the writing of the manuscript: Kimoto, Vourvahis, Scialis, Eng, Rodrigues, Varma.

\section{References}

Abel S, Back DJ, and Vourvahis M (2009) Maraviroc: pharmacokinetics and drug interactions. Antivir Ther 14:607-618.

Abel S, Jenkins TM, Whitlock LA, Ridgway CE, and Muirhead GJ (2008a) Effects of CYP3A4 inducers with and without CYP3A4 inhibitors on the pharmacokinetics of maraviroc in healthy volunteers. Br J Clin Pharmacol 65 (Suppl 1):38-46.

Abel S, Russell D, Taylor-Worth RJ, Ridgway CE, and Muirhead GJ (2008b) Effects of CYP3A4 inhibitors on the pharmacokinetics of maraviroc in healthy volunteers. Br J Clin Pharmacol 65 (Suppl 1):27-37.

Abel S, Russell D, Whitlock LA, Ridgway CE, Nedderman AN, and Walker DK (2008c) Assessment of the absorption, metabolism and absolute bioavailability of maraviroc in healthy male subjects. Br J Clin Pharmacol 65 (Suppl 1):60-67.

Barnett S, Ogungbenro K, Ménochet K, Shen H, Lai Y, Humphreys WG, and Galetin A (2018) Gaining mechanistic insight into coproporphyrin I as endogenous biomarker for OATP1Bmediated drug-drug interactions using population pharmacokinetic modeling and simulation. Clin Pharmacol Ther 104:564-574.

Bi YA, Qiu X, Rotter CJ, Kimoto E, Piotrowski M, Varma MV, Ei-Kattan AF, and Lai Y (2013) Quantitative assessment of the contribution of sodium-dependent taurocholate co-transporting polypeptide (NTCP) to the hepatic uptake of rosuvastatin, pitavastatin and fluvastatin. Biopharm Drug Dispos 34:452-461.

Chen J and Raymond K (2006) Roles of rifampicin in drug-drug interactions: underlying molecular mechanisms involving the nuclear pregnane X receptor. Ann Clin Microbiol Antimicrob 5:3.

Chen Y, Liu L, Monshouwer M, and Fretland AJ (2011) Determination of time-dependent in activation of CYP3A4 in cryopreserved human hepatocytes and assessment of human drug-drug interactions. Drug Metab Dispos 39:2085-2092

Chu X, Cai X, Cui D, Tang C, Ghosal A, Chan G, Green MD, Kuo Y, Liang Y, Maciolek CM, et al. (2013) In vitro assessment of drug-drug interaction potential of boceprevir associated with drug metabolizing enzymes and transporters. Drug Metab Dispos 41:668-681.

Fahmi OA, Hurst S, Plowchalk D, Cook J, Guo F, Youdim K, Dickins M, Phipps A, Darekar A, Hyland R, et al. (2009) Comparison of different algorithms for predicting clinical drug-drug interactions, based on the use of CYP3A4 in vitro data: predictions of compounds as precipitants of interaction. Drug Metab Dispos 37:1658-1666.

Fujita Y, Noguchi K, Suzuki T, Katayama K, and Sugimoto Y (2013) Biochemical interaction of anti-HCV telaprevir with the $\mathrm{ABC}$ transporters P-glycoprotein and breast cancer resistance protein. BMC Res Notes 6:445.

Furihata T, Matsumoto S, Fu Z, Tsubota A, Sun Y, Matsumoto S, Kobayashi K, and Chiba K (2014) Different interaction profiles of direct-acting anti-hepatitis $C$ virus agents with human organic anion transporting polypeptides. Antimicrob Agents Chemother 58:4555-4564. 
Gnoth MJ, Buetehorn U, Muenster U, Schwarz T, and Sandmann S (2011) In vitro and in vivo P-glycoprotein transport characteristics of rivaroxaban. J Pharmacol Exp Ther 338:372-380.

Greiner B, Eichelbaum M, Fritz P, Kreichgauer HP, von Richter O, Zundler J, and Kroemer HK (1999) The role of intestinal P-glycoprotein in the interaction of digoxin and rifampin. J Clin Invest 104: 147-153.

Gui C and Hagenbuch B (2009) Role of transmembrane domain 10 for the function of organic anion transporting polypeptide 1B1. Protein Sci 18:2298-2306.

Hyland R, Dickins M, Collins C, Jones H, and Jones B (2008) Maraviroc: in vitro assessment of drug-drug interaction potential. Br J Clin Pharmacol 66:498-507.

Karlgren M, Vildhede A, Norinder U, Wisniewski JR, Kimoto E, Lai Y, Haglund U, and Artursson P (2012) Classification of inhibitors of hepatic organic anion transporting polypeptides (OATPs): influence of protein expression on drug-drug interactions. J Med Chem 55:4740-4763.

Kimoto E, Bi YA, Kosa RE, Tremaine LM, and Varma MVS (2017) Hepatobiliary clearance prediction: species scaling from monkey, dog, and rat, and in vitro-in vivo extrapolation of sandwich-cultured human hepatocytes using 17 drugs. J Pharm Sci 106:2795-2804.

Kimoto E, Chupka J, Xiao Y, Bi YA, and Duignan DB (2011) Characterization of digoxin uptake in sandwich-cultured human hepatocytes. Drug Metab Dispos 39:47-53.

Kimoto E, Li R, Scialis RJ, Lai Y, and Varma MV (2015) Hepatic disposition of gemfibrozil and its major metabolite gemfibrozil 1-O- $\beta$-glucuronide. Mol Pharm 12:3943-3952.

Kirby BJ, Collier AC, Kharasch ED, Whittington D, Thummel KE, and Unadkat JD (2012) Complex drug interactions of the HIV protease inhibitors 3: effect of simultaneous or staggered dosing of digoxin and ritonavir, nelfinavir, rifampin, or bupropion. Drug Metab Dispos 40:610-616.

Kishimoto W, Ishiguro N, Ludwig-Schwellinger E, Ebner T, and Schaefer O (2014) In vitro predictability of drug-drug interaction likelihood of P-glycoprotein-mediated efflux of dabigatran etexilate based on []$_{2} / \mathrm{IC}_{50}$ threshold. Drug Metab Dispos 42:257-263.

Kunze A, Huwyler J, Camenisch G, and Gutmann H (2012) Interaction of the antiviral drug telaprevir with renal and hepatic drug transporters. Biochem Pharmacol 84:1096-1102.

Mao J, Johnson TR, Shen Z, and Yamazaki S (2013) Prediction of crizotinib-midazolam interaction using the Simcyp population-based simulator: comparison of CYP3A time-dependent inhibition between human liver microsomes versus hepatocytes. Drug Metab Dispos 41:343-352.

Mao J, Tay S, Khojasteh CS, Chen Y, Hop CE, and Kenny JR (2016) Evaluation of time dependent inhibition assays for marketed oncology drugs: comparison of human hepatocytes and liver microsomes in the presence and absence of human plasma. Pharm Res 33:1204-1219.

Mikkaichi T, Yoshigae Y, Masumoto H, Imaoka T, Rozehnal V, Fischer T, Okudaira N, and Izumi T (2014) Edoxaban transport via P-glycoprotein is a key factor for the drug's disposition. Drug Metab Dispos 42:520-528.

Mouly S, Lown KS, Kornhauser D, Joseph JL, Fiske WD, Benedek IH, and Watkins PB (2002) Hepatic but not intestinal CYP3A4 displays dose-dependent induction by efavirenz in humans. Clin Pharmacol Ther 72:1-9.

Noé J, Portmann R, Brun ME, and Funk C (2007) Substrate-dependent drug-drug interactions between gemfibrozil, fluvastatin and other organic anion-transporting peptide (OATP) substrates on OATP1B1, OATP2B1, and OATP1B3. Drug Metab Dispos 35:1308-1314.

Oda K and Yamano K (2014) Effect of telaprevir on the metabolism and hepatic uptake of tacrolimus (FK506). Biopharm Drug Dispos 35:501-512.

Ogasawara A, Kume T, and Kazama E (2007) Effect of oral ketoconazole on intestinal firstpass effect of midazolam and fexofenadine in cynomolgus monkeys. Drug Metab Dispos 35: $410-418$

Ohnishi S, Hays A, and Hagenbuch B (2014) Cysteine scanning mutagenesis of transmembrane domain 10 in organic anion transporting polypeptide 1B1. Biochemistry 53:2261-2270.

Oswald S, Meyer zu Schwabedissen HE, Nassif A, Modess C, Desta Z, Ogburn ET, Mostertz J, Keiser M, Jia J, Hubeny A, et al. (2012) Impact of efavirenz on intestinal metabolism and transport: insights from an interaction study with ezetimibe in healthy volunteers. Clin Pharmacol Ther 91:506-513

Penzak SR, Shen JM, Alfaro RM, Remaley AT, Natarajan V, and Falloon J (2004) Ritonavir decreases the nonrenal clearance of digoxin in healthy volunteers with known MDR1 genotypes. Ther Drug Monit 26:322-330.

Platt L, Easterbrook P, Gower E, McDonald B, Sabin K, McGowan C, Yanny I, Razavi H, and Vickerman P (2016) Prevalence and burden of HCV co-infection in people living with HIV a global systematic review and meta-analysis. Lancet Infect Dis 16:797-808.

Rodgers T, Leahy D, and Rowland M (2005) Physiologically based pharmacokinetic modeling 1 : predicting the tissue distribution of moderate-to-strong bases. J Pharm Sci 94:1259-1276.

Rodgers T and Rowland M (2006) Physiologically based pharmacokinetic modelling 2: predicting the tissue distribution of acids, very weak bases, neutrals and zwitterions. J Pharm Sci 95:1238-1257.

Roth M, Timmermann BN, and Hagenbuch B (2011) Interactions of green tea catechins with organic anion-transporting polypeptides. Drug Metab Dispos 39:920-926.

Shebley M, Fu W, Badri P, Bow D, and Fischer V (2017) Physiologically based pharmacokinetic modeling suggests limited drug-drug interaction between clopidogrel and dasabuvir. Clin Pharmacol Ther 102:679-687.

Shitara Y and Sugiyama Y (2017) Preincubation-dependent and long-lasting inhibition of organic anion transporting polypeptide (OATP) and its impact on drug-drug interactions. Pharmaco Ther 177:67-80.

Siccardi M, D'Avolio A, Nozza S, Simiele M, Baietto L, Stefani FR, Moss D, Kwan WS, Castagna A Lazzarin A, et al. (2010) Maraviroc is a substrate for OATP1B1 in vitro and maraviroc plasma concentrations are influenced by SLCO1B1 $521 \mathrm{~T}>\mathrm{C}$ polymorphism. Pharmacogenet Genomics 20:759-765.

Takahashi T, Ohtsuka T, Uno Y, Utoh M, Yamazaki H, and Kume T (2016) Pre-incubation with cyclosporine A potentiates its inhibitory effects on pitavastatin uptake mediated by recombinantly expressed cynomolgus monkey hepatic organic anion transporting polypeptide. Biopharm Drug Dispos 37:479-490.

Tamai I, Nozawa T, Koshida M, Nezu J, Sai Y, and Tsuji A (2001) Functional characterization of human organic anion transporting polypeptide B (OATP-B) in comparison with liver-specific OATP-C. Pharm Res 18:1262-1269.

Tseng E, Fate GD, Walker GS, Goosen TC, and Obach RS (2018) Biosynthesis and identification of metabolites of maraviroc and their use in experiments to delineate the relative contributions of cytochrome P4503A4 versus 3A5. Drug Metab Dispos 46:493-502.

Varma MV, Bi YA, Kimoto E, and Lin J (2014) Quantitative prediction of transporter- and enzyme-mediated clinical drug-drug interactions of organic anion-transporting polypeptide 1B1 substrates using a mechanistic net-effect model. J Pharmacol Exp Ther 351:214-223.

Varma MV, Kimoto E, Scialis R, Bi Y, Lin J, Eng H, Kalgutkar AS, El-Kattan AF, Rodrigues AD, and Tremaine LM (2017) Transporter-mediated hepatic uptake plays an important role in the pharmacokinetics and drug-drug interactions of montelukast. Clin Pharmacol Ther 101:406-415

Varma MV, Lai Y, Feng B, Litchfield J, Goosen TC, and Bergman A (2012) Physiologically based modeling of pravastatin transporter-mediated hepatobiliary disposition and drug-drug interactions. Pharm Res 29:2860-2873.

Varma MV, Lin J, Bi YA, Rotter CJ, Fahmi OA, Lam JL, El-Kattan AF, Goosen TC, and Lai Y (2013) Quantitative prediction of repaglinide-rifampicin complex drug interactions using dynamic and static mechanistic models: delineating differential CYP3A4 induction and OATP1B1 inhibition potential of rifampicin. Drug Metab Dispos 41:966-974.

Varma MV, Pang KS, Isoherranen N, and Zhao P (2015) Dealing with the complex drug-drug interactions: towards mechanistic models. Biopharm Drug Dispos 36:71-92.

Vieira ML, Kirby B, Ragueneau-Majlessi I, Galetin A, Chien JY, Einolf HJ, Fahmi OA, Fischer V, Fretland A, Grime K, et al. (2014) Evaluation of various static in vitro-in vivo extrapolation models for risk assessment of the CYP3A inhibition potential of an investigational drug. Clin Pharmacol Ther 95:189-198.

Vourvahis M, Plotka A, Kantaridis C, Fang A, and Heera J (2014) The effects of boceprevir and telaprevir on the pharmacokinetics of maraviroc: an open-label, fixed-sequence study in healthy volunteers. J Acquir Immune Defic Syndr 65:564-570.

Vourvahis M, Sanders F, Malarstig A, Morgan P, Fenner KS, Wood LS, Lin CY, Ullah M, Kempshall S, Siccardi M, et al. (2011) Impact of genetic variants of OATP1B1 (SLCO1B1) on maraviroc pharmacokinetics, in 13th European AIDS Conference (EACS), Belgrade, Serbia.

Wagner C, Zhao P, Pan Y, Hsu V, Grillo J, Huang SM, and Sinha V (2015) Application of physiologically based pharmacokinetic (PBPK) modeling to support dose selection: report of an FDA public workshop on PBPK. CPT Pharmacometrics Syst Pharmacol 4:226-230.

Walker DK, Abel S, Comby P, Muirhead GJ, Nedderman AN, and Smith DA (2005) Species differences in the disposition of the CCR5 antagonist, UK-427,857, a new potential treatment for HIV. Drug Metab Dispos 33:587-595

Wang X, Wolkoff AW, and Morris ME (2005) Flavonoids as a novel class of human organic anion-transporting polypeptide OATP1B1 (OATP-C) modulators. Drug Metab Dispos 33: $1666-1672$.

Weiss J, Becker JP, and Haefeli WE (2014) Telaprevir is a substrate and moderate inhibitor of P-glycoprotein, a strong inductor of ABCG2, but not an activator of PXR in vitro. Int J Antimicrob Agents 43:184-188.

White PW, Llinàs-Brunet M, Amad M, Bethell RC, Bolger G, Cordingley MG, Duan J, Garneau M, Lagacé L, Thibeault D, et al. (2010) Preclinical characterization of BI 201335, a C-terminal carboxylic acid inhibitor of the hepatitis C virus NS3-NS4A protease. Antimicrob Agents Chemother 54:4611-4618.

Wlcek K, Koller F, Ferenci P, and Stieger B (2013) Hepatocellular organic anion-transporting polypeptides (OATPs) and multidrug resistance-associated protein 2 (MRP2) are inhibited by silibinin. Drug Metab Dispos 41:1522-1528.

Xu L, Chen Y, Pan Y, Skiles GL, and Shou M (2009) Prediction of human drug-drug interactions from time-dependent inactivation of CYP3A4 in primary hepatocytes using a population-based simulator. Drug Metab Dispos 37:2330-2339.

Yates P, Eng H, Di L, and Obach RS (2012) Statistical methods for analysis of time-dependent inhibition of cytochrome P450 enzymes. Drug Metab Dispos 40:2289-2296.

Yoshikado T, Yoshida K, Kotani N, Nakada T, Asaumi R, Toshimoto K, Maeda K, Kusuhara H, and Sugiyama Y (2016) Quantitative analyses of hepatic OATP-mediated interactions between statins and inhibitors using PBPK modeling with a parameter optimization method. Clin Pharmacol Ther 100:513-523.

Zhang T (2015) Physiologically based pharmacokinetic modeling of disposition and drug-drug interactions for atorvastatin and its metabolites. Eur J Pharm Sci 77:216-229.

Address correspondence to: Dr. Emi Kimoto, Pharmacokinetics, Dynamics, and Metabolism, Medicine Design, Pfizer Inc., Eastern Point Road, Groton, CT 06340. E-mail: emi.kimoto@pfizer.com 